\title{
Experience and Activity-Dependent Maturation of Perisomatic GABAergic Innervation in Primary Visual Cortex during a Postnatal Critical Period
}

\author{
Bidisha Chattopadhyaya, ${ }^{1,2 *}$ Graziella Di Cristo, ${ }^{1 \star}$ Hiroyuki Higashiyama, ${ }^{1}$ Graham W. Knott, ${ }^{3}$ Sandra J. Kuhlman, ${ }^{1}$ \\ Egbert Welker, ${ }^{3}$ and Z. Josh Huang ${ }^{1}$ \\ ${ }^{1}$ Cold Spring Harbor Laboratory, Cold Spring Harbor, New York 11724, 2Department of Neurobiology, State University of New York, Stony Brook, New York \\ 11790, and ${ }^{3}$ Institute de Biologie Cellularie et de Morphologie, University of Lausanne, CH 1005 Lausanne, Switzerland
}

\begin{abstract}
The neocortical GABAergic network consists of diverse interneuron cell types that display distinct physiological properties and target their innervations to subcellular compartments of principal neurons. Inhibition directed toward the soma and proximal dendrites is crucial in regulating the output of pyramidal neurons, but the development of perisomatic innervation is poorly understood because of the lack of specific synaptic markers. In the primary visual cortex, for example, it is unknown whether, and to what extent, the formation and maturation of perisomatic synapses are intrinsic to cortical circuits or are regulated by sensory experience. Using bacterial artificial chromosome transgenic mice that label a defined class of perisomatic synapses with green fluorescent protein, here we show that perisomatic innervation developed during a protracted postnatal period after eye opening. Maturation of perisomatic innervation was significantly retarded by visual deprivation during the third, but not the fifth, postnatal week, implicating an important role for sensory input. To examine the role of cortical intrinsic mechanisms, we developed a method to visualize perisomatic synapses from single basket interneurons in cortical organotypic cultures. Characteristic perisomatic synapses formed through a stereotyped process, involving the extension of distinct terminal branches and proliferation of perisomatic boutons. Neuronal spiking in organotypic cultures was necessary for the proliferation of boutons and the extension, but not the maintenance, of terminal branches. Together, our results suggest that although the formation of perisomatic synapses is intrinsic to the cortex, visual experience can influence the maturation and pattern of perisomatic innervation during a postnatal critical period by modulating the level of neural activity within cortical circuits.
\end{abstract}

Key words: GABAergic; perisomatic synapse; visual cortex; critical period; experience; BAC transgenic

\section{Introduction}

The cortical GABAergic system consists of an array of interneuron cell types that display distinct morphology, physiological properties, and synaptic connectivity patterns (Freund et al., 1996; Gupta et al., 2000; McBain and Fisahn, 2001). A prominent feature of GABAergic innervation is the preferential targeting of specific classes of GABAergic synapses to subcellular compartments of principal neurons (i.e., spines, dendrite, soma, and axon initial segment) (Somogyi et al., 1998). These distinct classes of GABAergic synapses contribute to the differential regulation of pyramidal neurons. Although dendritic inhibition is likely to control the efficacy and plasticity of excitatory inputs onto principal neurons (Miles et al., 1996; Tamas et al., 1997, 2003), perisomatic inhibition is ideally suited to control the output, syn-

Received May 12, 2004; revised July 26, 2004; accepted Sept. 7, 2004

This work was supported by the Whitehall Foundation and National Institutes of Health Grant R01 EY13564-01. G.D. is a Long-Term European Molecular Biology Organization Fellow. Z.J.H. is a Pew and McKnight Scholar. We thank Tim Pal for technical assistance, Ed Ruthazer for help with macros in three-dimensional Sholl analysis, and Ed Ruthazer and especially Holly Cline, Rachel Wong, and Karel Svoboda for critical reading of this manuscript.

*B.C. and G.D. contributed equally to this work.

Correspondence should be addressed to Dr. Z. Josh Huang at the above address. E-mail: huangj@cshl.edu. D0I:10.1523/JNEUROSCI.1851-04.2004

Copyright $\odot 2004$ Society for Neuroscience $\quad$ 0270-6474/04/249598-14\$15.00/0 chronizing the action potential firing of large groups of principal cells (Miles et al., 1996; Tamas et al., 1997). To understand the development of GABAergic circuits and synapses, it is therefore crucial to distinguish among different classes of synapses, which may take distinct developmental time courses and involve different regulatory and plasticity mechanisms. However, the heterogeneity of GABAergic circuits has thus far precluded the study of the development of specific classes of inhibitory synapses. For example, although perisomatic inhibition is likely essential for all operations of cortical circuits, the development and plasticity of perisomatic GABAergic innervation are poorly understood because of the lack of specific synaptic markers.

In rodent primary visual cortex, the functional maturation of GABAergic inhibition proceeds during a protracted postnatal period from the time of eye opening to early adulthood (Huang et al., 1999; Morales et al., 2002) and likely involves an increase of GABAergic synapses converging onto pyramidal neurons (Bahr et al., 1985; Miller, 1986; Morales et al., 2002). Visual deprivation has been shown to retard the developmental increase of GABAergic inhibition (Benevento et al., 1992, 1995; Morales et al., 2002; Gianfranceschi et al., 2003), but the cellular and synaptic basis underlying the developmental and experience-dependent maturation of GABAergic inhibition is unknown, mostly because of 
the heterogeneity of GABAergic cell types. Perisomatic innervation mediated by basket interneurons, which constitutes up to $50 \%$ of GABAergic interneurons in the visual cortex, is likely a component of the overall developmental and experiencedependent maturation of GABAergic innervation in the primary visual cortex.

In mature cortex, a single basket interneuron is estimated to innervate hundreds of pyramidal neurons (Holmgren et al., 2003), and each pyramidal neuron receives inputs from multiple basket cells (Somogyi et al., 1998; Holmgren et al., 2003). At each postsynaptic target, a basket cell axon extends multiple terminals with large boutons clustered around pyramidal cell soma and proximal dendrites, forming the characteristic perisomatic synapses (Tamas et al., 1997; Wang et al., 2002). The postnatal maturation of perisomatic innervation would thus generate appropriate patterns of perisomatic synapses among pyramidal neurons within cortical circuits. The development of perisomatic innervation in the primary visual cortex has not been characterized because of the lack of specific markers. In particular, it is not known whether, and to what extent, the formation of perisomatic synapses and maturation of perisomatic innervation are intrinsic properties of cortical circuits, or are regulated by sensory experience.

Perisomatic synapses mainly arise from two distinct subclasses of basket interneurons, those containing either the calcium-binding protein parvalbumin $(\mathrm{Pv})$ or the neuropeptide cholecystokinin (CCK) (Freund, 2003). Using cell type-specific promoters and bacterial artificial chromosome (BAC) engineering (Heintz et al., 2001), we have generated BAC transgenic mice that selectively express green fluorescent protein (GFP) in the Pv-expressing subclass of basket interneurons, which allowed reliable and efficient characterization of perisomatic innervation in vivo. Here, we demonstrate a prolonged maturation of perisomatic innervation in the primary visual cortex from eye opening well into early adulthood, which is significantly retarded by visual deprivation during a restricted postnatal time window. To examine the role of cortical intrinsic mechanism in the development of perisomatic innervation, we developed a method to visualize perisomatic synapses of individual basket interneurons in cortical organotypic cultures. We show that the formation of characteristic perisomatic synapses around individual pyramidal neurons is, in fact, a rather stereotyped process that can proceed in the absence of thalamic inputs. In contrast, neuronal activity strongly regulates the extension of basket cell axon terminal branches and proliferation of perisomatic boutons around pyramidal neurons, establishing a link between experiencedependent and cortical intrinsic mechanisms.

We therefore suggest that although the formation of perisomatic synapses is intrinsic to the cortex, visual experience can influence the maturation and pattern of perisomatic innervation during a postnatal critical period by modulating the level of neural activity within cortical circuits.

\section{Materials and Methods}

$B A C$ engineering

$B A C$ engineering and transgenic mice. BAC clones containing the mouse $\mathrm{Pv}$ and GAD67 genes were identified from the RPCI-23 library (Research Genetics, Huntsville, AL) using two strategies. First, high-density filters of the RPCI-24 library (Research Genetics) were screened with $\mathrm{P}^{32}$. labeled genomic DNA probes. Second, we developed a bioinformatics program that can rapidly identify BAC clones and contigs containing any gene of interest. This program uses genomic sequence of genes of interest (Celera database) to screen the BAC Ends Sequence Database (The Institute for Genomic Research) and then identifies, maps, and aligns all BAC clones within the defined genomic region. We selected BAC clones containing genes of interest and defined length of $5^{\prime}$ and $3^{\prime}$ regulatory regions for BAC engineering. The identity and size of BAC clones were confirmed by pulse field gel electrophoresis and Southern blotting. The mouse GAD67 gene contains 16 exons spanning a $70 \mathrm{~kb}$ genomic region (see Fig. 4). A BAC clone containing the entire gene and $60 \mathrm{~kb}$ of upstream and downstream regions was used for BAC modifications. GFP expression cassettes were inserted in the first coding exon at the translation initiation site of the gene of interest using a procedure developed by Yang et al. (1997). Briefly, a recombination "building vector" was constructed in which the enhanced GFP (EGFP) cDNA and the phosphoglycerate kinase polyadenylation sequence were flanked by multiple cloning sites. A 5' homology sequence and a 3' homology sequence from the GAD67 gene were inserted at the HindIII and XbaI sites, respectively, of the building vector to produce GAD67-GFP/BV. The recombination cassette was excised as the SalI fragment and transferred to the recombination shuttle vector to produce GAD67-GFP/SV. BAC recombinations were performed as described by Yang et al. (1997). GFP-modified BAC clones were confirmed by PCR, pulse field gel electrophoresis, and Southern blotting. Circular BAC DNAs were injected into the fertilized eggs of the C57BL/ 6 strain at a concentration of $0.5 \mathrm{ng} / \mu \mathrm{l}$ in microinjection buffer ( 10 mM Tris, $\mathrm{pH} 7.4$, and 0.15 mm EDTA, pH 8.0) using standard procedures. Four transgenic founders were identified of 39 pups by PCR and confirmed by Southern blotting. A GFP expression pattern was analyzed in fixed brain sections. Based on the GFP expression level and pattern, line G42 was chosen for this study. All G42 mice were analyzed as heterozygotes.

Subcloning of $P_{G 67}$ promoter by gap repair. The EGFP coding region in pEGFP-1 (Clontech, Cambridge, UK) was replaced with a DNA segment from our modified GAD67-GFP BAC clone, which contains a $10 \mathrm{~kb}$ promoter region of GAD67, followed by an EGFP cassette. Subcloning by gap repair was achieved using a $\lambda$-prophage-based BAC engineering system recombination (Lee et al., 2001). Briefly, the modified GAD67-GFP BAC clone was transferred into recombination-competent EL250 strain by electroporation. To generate a DNA fragment for recombination and subcloning, two PCR primers were designed. The $3^{\prime}$ portion of the primers are homologous to the promoterless mammalian expression vector pEGFP-1 (Clontech). The $5^{\prime}$ portions of the primers are homologous to regions of GAD67-GFP to be subcloned: one primer is $\sim 10 \mathrm{~kb}$ from the translation start of GFP, and the other primer is at the end of the GFP coding region. Linearized pEGFP-1 vector backbone was amplified using chimeric primers and used for homologous recombination (Lee et al., 2001). Subcloned GAD67-GFP genomic segments were selected for kanamycin and verified by restriction digestion and DNA sequencing.

\section{Slice culture and biolistic transfection}

Slice culture preparation was essentially as described (Stoppini et al., 1991). Postnatal day 2 (P2) to P5 mouse pups were decapitated, and brains were rapidly removed and immersed in ice-cold artificial lowsodium CSF (ACSF) containing $4 \mathrm{~mm} \mathrm{KCl,} 5 \mathrm{~mm} \mathrm{MgCl}_{2}, 1 \mathrm{mM} \mathrm{CaCl}_{2}, 26$ $\mathrm{mm} \mathrm{NaHCO}_{3}, 10 \mathrm{~mm}$ glucose, and $8 \%$ sucrose, saturated with $95 \%$ $\mathrm{O}_{2} / 5 \% \mathrm{CO}_{2}$. Coronal brain slices of the occipital cortex, $400 \mu \mathrm{m}$ thick, were cut with a Chopper (Stoelting, Wood Dale, IL) into ice-cold ACSF. Slices were then placed on transparent Millicell membrane inserts (Millipore, Bedford, MA), usually two slices/insert, in $30 \mathrm{~mm}$ Petri dishes containing $1 \mathrm{ml}$ of culture medium (containing DMEM, 20\% horse serum, $1 \mathrm{~mm}$ glutamine, $13 \mathrm{~mm}$ glucose, $1 \mathrm{~mm} \mathrm{CaCl}_{2}, 2 \mathrm{~mm} \mathrm{MgSO}_{4}, 0.5$ $\mu \mathrm{m} / \mathrm{ml}$ insulin, $30 \mathrm{~mm}$ HEPES, $5 \mathrm{~mm} \mathrm{NaHCO}$, and $0.001 \%$ ascorbic acid). Finally, they were incubated in a humidified incubator at $34^{\circ} \mathrm{C}$ with a $5 \% \mathrm{CO}_{2}$-enriched atmosphere, and the medium was changed three times per week. All procedures were performed under sterile conditions. In experiments in which spiking activity was blocked, $1 \mu \mathrm{m}$ of TTX (Alomone Labs, Jerusalem, Israel) was added to the culture medium during the specific time window. To control for potential toxic effects of TTX on the cultures, pyramidal cell density was evaluated in TTX-treated and control age-matched cultures by counting the number of $\beta$-galactosidase ( $\beta$-gal)-positive cells in a volume of $146.2 \times 146.2 \times 10$ $\mu \mathrm{m}$ (defined confocal image stacks acquired with a $63 \times$ objective; see below). 
Constructs to be transfected were incorporated into "bullets" that are made using $1.6 \mu \mathrm{m}$ gold particles coated with $50 \mu \mathrm{g}$ of the DNA of interest. These bullets were used to biolistically transfect slices by gene gun (Bio-Rad, Hercules, CA) at high pressure $(180 \psi)$, and the transfected slices were incubated for $72 \mathrm{hr}$ under the same conditions as described above, before imaging.

\section{Electrophysiology recording}

GFP-expressing neurons in organotypic cultures were visualized using an Axioskop FS2 microscope (Zeiss, Thornwood, NY) equipped with near-infrared differential interference contrast optics, narrow band GFP filter set (Chroma Technology, Brattleboro, VT), a $63 \times$ objective, numerical aperture (NA) 0.95 (Zeiss), and cooled charged-coupled devise camera (ORCA-ER; Hamamatsu, Hamamatsu City, Japan). Whole-cell current-clamp recordings were made from slices submerged in ACSF [in mM: $126 \mathrm{NaCl}, 2.5 \mathrm{KCl}, 1.25 \mathrm{NaH}_{2} \mathrm{PO}_{4}, 1 \mathrm{MgSO}_{4}, 2 \mathrm{CaCl}_{2}, 10 \mathrm{D}(+)-$ glucose, and $25 \mathrm{NaCHO}_{3}$; continuously bubbled with $95 \% \mathrm{O}_{2} / 5 \% \mathrm{CO}_{2}$ ], perfused at a rate of $2-3 \mathrm{ml} / \mathrm{min}\left(33 \pm 1^{\circ} \mathrm{C}\right)$. Pipettes were filled with intracellular solution [in mM: $135 \mathrm{~K}$-gluconate, $4.3 \mathrm{KCl}, 2 \mathrm{NaCl}, 10$ HEPES, 0.5 EGTA, 4 MgATP, 20 phosphocreatine(Na), and $0.3 \mathrm{NaGTP}$, $\mathrm{pH} 7.3,300 \mathrm{mOsm}$ ] having a resistance of $2-4 \mathrm{M} \Omega$. Data were acquired at $10 \mathrm{kHz}$ and low-pass filtered at $6 \mathrm{kHz}$. Electrophysiological signals were processed and controlled by a Multiclamp 700A amplifier, Digidata 1322 analog-to-digital converter, and Clampex9 software (Axon Instruments, Union City, CA).

\section{Analysis of perisomatic innervation in visual cortex}

Immunohistochemistry and confocal microscopy. Mice were anesthetized (sodium pentobarbitone; $6 \mathrm{mg} / 100 \mathrm{gm}$ body weight) and perfused transcardially with $4 \%$ paraformaldehyde in phosphate buffer, $\mathrm{pH} 7.4$. Sixtymicrometer-thick coronal sections were cut from the visual cortex using a vibratome (Leica VT100; Leica, Nussloch, Germany). Brain sections were blocked in 10\% NGS and 1\% Triton. Slices were then incubated overnight at $4^{\circ} \mathrm{C}$ in $10 \% \mathrm{NGS}$ and $0.1 \%$ Triton and the following primary antibodies: GAD65 (monoclonal antibody; 1:1000; Chemicon, Temecula, CA), NeuN (a monoclonal antibody that specifically labels neuronal nuclei; 1:400; Chemicon), Pv (monoclonal antibody; 1:1000; Sigma, St. Louis, MO), somatostatin (SOM; rabbit polyclonal antibody; 1:1000; Chemicon), calretinin (CR; goat polyclonal antibody; 1: 1000; Chemicon), and CKK (monoclonal antibody \#9303; 1:1000; CURE/Digestive Disease Research Center, Vaglahs, CA). Sections were then incubated with appropriate Alexa594-conjugated goat IgG (1: 400; Molecular Probes, Eugene, OR) and mounted. NeuN is thought to be a panneuronal marker. However, we discovered that, in our immunohistochemistry conditions, NeuN expression, in fact, was restricted to pyramidal neurons, but not GABAergic interneurons, in the neocortex. It is likely that NeuN may be expressed in interneurons at very low levels, below detection with our method. Freeze-thaw is known to increase exposure of antigen and sensitivity of immunostaining in brain tissue. We cut brain sections with a vibratome without freezing the brain, which may lower sensitivity of the NeuN antibody.

Image acquisition and analysis. Visual cortices from at least three animals were used for each developmental age and each experimental condition. Three coronal sections containing the primary visual cortex from each animal were analyzed. The binocular region of the primary visual cortex was identified by anatomical landmarks. Nonoverlapping images from a single confocal plane were acquired in layer $5 / 6$ with a $63 \times$ oil immersion objective (NA, 1.4; Zeiss) using a confocal microscope (Zeiss LSM510). Scans from each channel were collected in multiple track mode and subsequently merged. Care was taken to use the lowest laser power, and no bleedthrough was visible between Alexa594 and Alexa488 channels. Images were acquired using the same acquisition parameters for all the samples. Images were saved as TIFF files and analyzed with $\mathrm{NIH}$ Image software. Pyramidal cell somata were identified by NeuN immunofluorescence. To estimate GFP-positive perisomatic boutons around a pyramidal cell soma, an area was traced by a line, which enclosed the soma but was $2 \mu \mathrm{m}$ away from the soma membrane. GFP-positive puncta between 8 and 80 pixels in area (as estimated by measurements of samples of visually identified boutons) within this area were counted automatically using NIH Image software as bouton density, the number of boutons per pyramidal cell soma section. Bouton densities among pyramidal neurons from each animal were averaged. Values for animals of the same age were not statistically different and were pooled. For monocular TTX-injected mice, both the ipsilateral (nondeprived) and contralateral (deprived) cortex were analyzed and compared in each animal. All quantification was done blind to the ages of the animals and to TTX treatment. To graphically describe perisomatic innervation, a z-stack cross a NeuN-positive pyramidal cell soma was taken and projected (see Fig. 2, bottom).

Analysis of perisomatic synapse formation in organotypic cultures Organotypic cultures were fixed overnight at $4{ }^{\circ} \mathrm{C}$ in $4 \%$ paraformaldehyde in phosphate buffer, $\mathrm{pH} 7.4$, frozen and thawed in $30 \%$ sucrose in PBS, and subjected to immunofluorescence as described above for brain sections. Slice cultures from emx-nlslacZ-ires-cre knock-in mice were immunostained with monoclonal antibody against $\beta$-gal (1:200; Promega, Madison, WI). Confocal images of the basket cell axon arbors were taken between 60 and $100 \mu \mathrm{m}$ from the basket cell body using a $63 \times$ oil objective (NA, 1.4). Z-stacks were acquired with $1 \mu \mathrm{m}$ steps as described above, exported as TIFF files, and analyzed using NIH Image software. Green and red channels were separated using custom-made macros. Basket axons and boutons were traced in three-dimensional in the green channel (for a detailed description of the procedure, see Ruthazer at al., 2002), which were then superimposed on the red channel containing images of pyramidal cell nuclei. Care was taken to analyze only those pyramidal nuclei that were complete and well isolated. In our ThreeDimensional Sholl analysis, Sholl spheres with a $1 \mu \mathrm{m}$ increment from the center of a pyramidal nucleus were used to quantify basket axon terminal branch complexity and bouton density around the pyramidal cell soma. Axon branch complexity around a single pyramidal cell soma was quantified by the average number of intersections between basket cell axons and the Sholl spheres in the first $7 \mu \mathrm{m}$ from the center of the pyramidal cell nucleus. We choose $7 \mu \mathrm{m}$ as the limiting radius for a Sholl sphere because it approximates the average pyramidal cell soma diameter measured from pyramidal neurons immunostained with NeuN antibody. Between 5 and 10 pyramidal neurons were analyzed for each presynaptic basket cell, and at least six basket cells were analyzed for each experimental condition. The distribution of pyramidal cell classes were plotted against the average number of intersections between a Sholl sphere from the center of their nuclei and basket axon branches surrounding them, which represents the complexity of basket axon terminal branches in a given experimental condition (see Fig. $8 \mathrm{C1}$ ). In some cases, the number of intersections between basket axons and Sholl spheres were also plotted against the distance from the center pyramidal cell nuclei (see Fig. 8D2).

Bouton density around each pyramidal cell soma was measured within the same set of Sholl spheres and averaged among pyramidal neurons for each condition. Bouton size was measured by the diameter of a bouton perpendicular to the basket axon around pyramidal cell soma using Zeiss confocal software. Only pyramidal cell somata with Sholl spheres, which intersect basket axons in the first $7 \mu \mathrm{m}$ from the center of their nuclei, were taken for analysis. All quantification was done blind of culture age or TTX treatment.

\section{Statistical analysis}

Differences between groups were assessed with Kruskal-Wallis one-way ANOVA on ranks with Dunn's post hoc test for not normally distributed data. Differences in bouton density and bouton size between TTXtreated cultures and age-matched control were assessed with the MannWhitney $U$ test for not normally distributed data. The same procedure was applied when the ipsilateral (nondeprived) and contralateral (deprived) cortices were compared in animals that receive monocular TTX injection. Differences in basket cell axon branch complexity between TTX-treated cultures and control were assessed with the $\chi^{2}$ test on the distribution of pyramidal cell classes.

\section{Intravitreal TTX injections}

Injections ( 3 mм TTX in $0.02 \mathrm{~m}$ citrate buffer; Alomone Labs) were performed daily under fluothane anesthesia, with a micropipette con- 

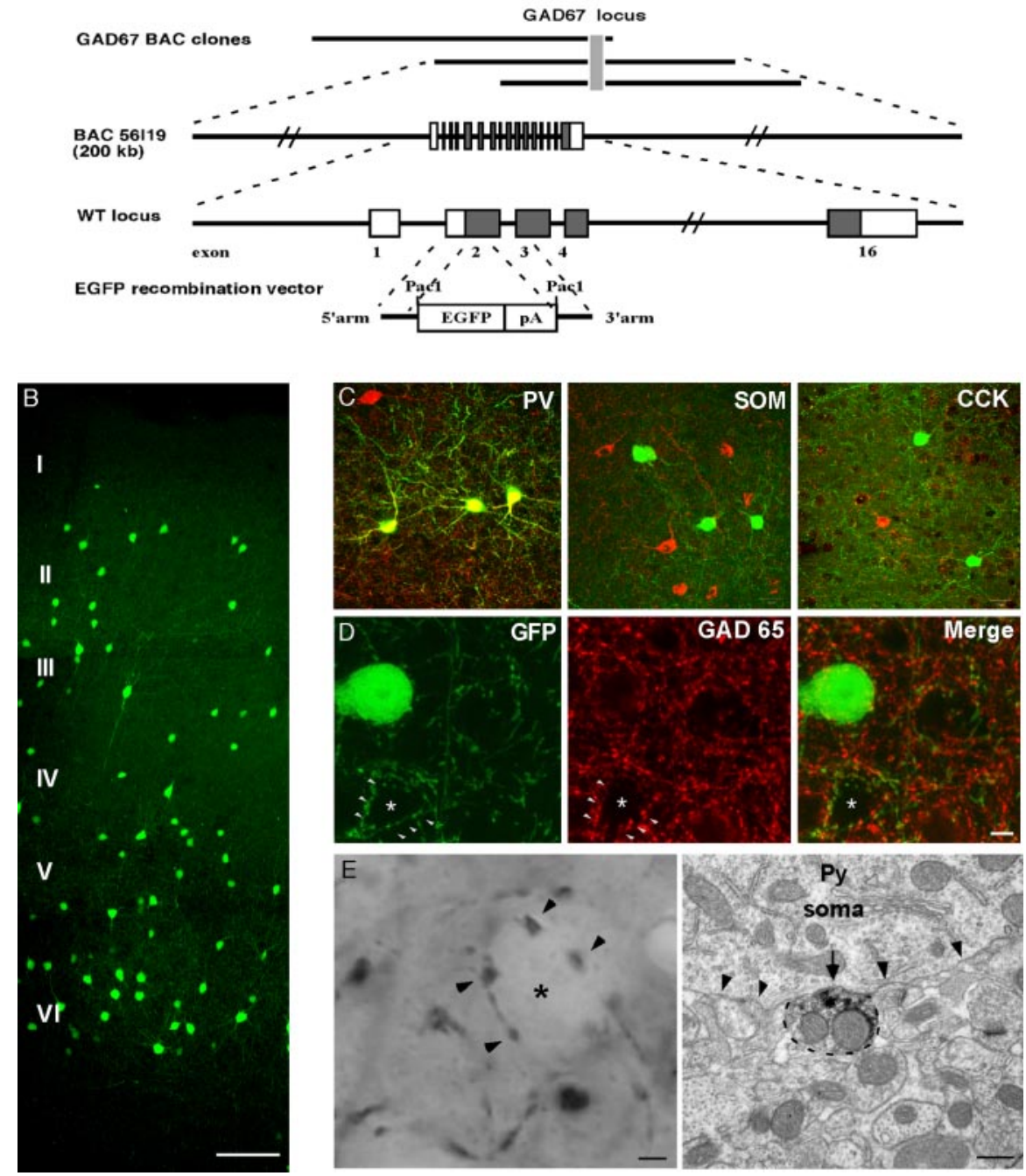

Figure 1. GFP BAC transgenic mice allow high-resolution labeling of Pv-positive basket interneurons and their soma-targeted presynaptic boutons. A, Scheme of GAD67 BAC engineering. Top, Diagram of overlapping BAC clones containing the mouse GAD67 gene. Bottom, Strategy for the modification of BAC clone 56119 with an EGFP recombination vector. An EGFP expression cassette was inserted at the translation initiation site in the second exon of the GAD67 gene. The GAD67 genomic structure is not drawn to scale. Open box, Noncoding exons; shaded box, coding exons; pA, phosphoglycerate kinase polyadenylation signal. Note that a gene of interest can be inserted into the recombination vector as a Pad fragment. $B$, GFP expression pattern in the visual cortex of a P28 GAD67-GFP mouse (G42 line). Cortical layers are indicated to the left. Scale bar, $100 \mu \mathrm{m}$. C, GFP-expressing cells are Pv immunopositive (PV; red) but do not express SOM (red) or CCK (red). Scale bar, $20 \mu \mathrm{m}$. D, Basket cell presynaptic boutons (arrowheads) surround pyramidal cell somata (asterisk) and contain GAD65 immunoreactivity (red) in mature primary visual cortex (P36). Scale bar, $5 \mu \mathrm{m}$. E, Left, Perisomatic boutons (arrowheads) visualized by GFP immunohistochemistry and light microscopy. The asterisks indicate neuronal soma. Scale bar, $2 \mu \mathrm{m}$. Right, A basket cell bouton (outlined by dashed lines) containing dark DAB precipitate, indicating the presence of GFP, is confirmed to be a presynaptic terminal of a symmetric synapse (arrow) on a cell soma (outlined by arrowheads) by immunoelectron microscopy. Scale bar, $0.5 \mu \mathrm{m}$.

nected to a microinjector. The micropipette was inserted at the ora serrata, and the injection volume $(<1 \mu \mathrm{l})$ was released slowly. Blockade of retinal activity was monitored by observing a tonic dilation of the pupil and loss of direct papillary response to eye illumination.

\section{Immuno electron microscopy}

P28 mice were anesthetized with sodium pentobarbitone $(6 \mathrm{mg} / 100 \mathrm{gm}$ body weight; intraperitoneally) and perfused immediately with $100 \mathrm{ml}$ of $0.2 \%$ glutaraldehyde and $2 \%$ paraformaldehyde in $0.1 \mathrm{M}$ phosphate buffer, $\mathrm{pH}$ 7.4. One hour after perfusion, the brains were removed, and $50 \mu \mathrm{m}$ vibratome (Leica VT100) sections were cut coronally from the visual cortex. Sections were cryoprotected in $2 \%$ glycerol and $20 \%$ DMSO in $0.1 \mathrm{M}$ PBS for $15 \mathrm{~min}$ and freeze thawed twice in liquid nitrogen. These were then incubated overnight in the primary antibody (GFP;
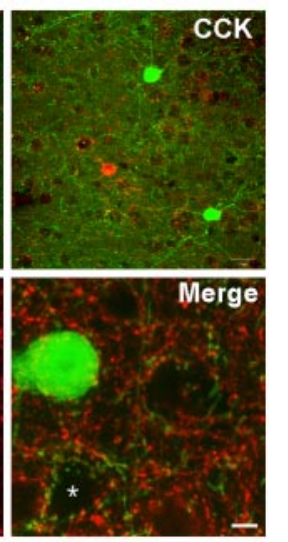

1:600; Chemicon) in PBS at $4^{\circ} \mathrm{C}$, then for $2 \mathrm{hr}$ at room temperature in biotinylated secondary antibody [goat antirabbit (F)ab fragment; 1:500; The Jackson Laboratory, Bar Harbor, $\mathrm{ME}$. To reveal the labeling, avidin-biotin-peroxidase complex (ABC Elite; Vector Laboratories, Burlingame, $\mathrm{CA}$ ) was used for $2 \mathrm{hr}$ and incubated in 3, $3^{\prime}$-diaminobenzidine tetrachloride (Fluka, Buchs, Switzerland) and 0.015\% hydrogen peroxide. After enhancement, the sections were then washed, postfixed in osmium tetroxide, and embedded in Epon resin (Fluka). Once cured, the regions of interest were localized with the light microscope, and this area was cut away from the section. This was then attached to a blank resin block and serially thin sectioned at a thickness of between 50 and $60 \mathrm{~nm}$. Images were acquired with a Philips CM12 electron microscope with a filament voltage of $80 \mathrm{kV}$ using a digital camera (Megaview 3; SIS, Münster, Germany).

\section{Results}

BAC transgenic mice allow

high-resolution visualization of basket interneurons and perisomatic synapses To visualize basket interneurons and their presynaptic terminals, we generated BAC transgenic mice expressing GFP under the control of either the $P v$ (a calcium-binding protein) or GAD67 (one of the two isoforms of glutamic acid decarboxylase) gene promoters. Through homologous recombination-based $\mathrm{BAC}$ engineering in bacteria, we inserted GFP coding sequence into BAC clones containing either the $P v$ (data not shown) or the GAD67 gene, at the translation initiation codon (Fig. $1 A$ ). In our Pv-GFP lines, GFP expression levels in basket interneurons in the visual cortex were not high enough to reliably visualize perisomatic synapses during early postnatal weeks (data not shown). These mice were not used in this study.

In one of the four GAD67-GFP lines (G42) (Fig. 1B), GFP expression was detected as early as P0 (data not shown), and the expression levels were high throughout postnatal development. Interestingly, all GFP-positive interneurons in the G42 mice became $\mathrm{Pv}$ positive in mature neocortex (92 of 92 GFP-positive cells coexpressed $\mathrm{Pv} ; n=3$ transgenic mice), and GFP expression remained restricted to $\sim 50 \%$ of $\mathrm{Pv}$ interneurons in adulthood (Fig. 1C, left). The number of GFP-expressing basket interneurons stabilized during the second postnatal week. GFP was not expressed in other interneuron classes positive for SOM (Fig. 1C, middle) (0 of 32 SOM-positive cells expressed GFP), CCK (Fig. 1C, right) (0 of 24 CCK-positive cells expressed GFP), and VIP and CR (data not shown, respectively; 0 of 15 VIP-positive and 0 of 20 CR-positive cells express GFP). Importantly, patch-clamp recording from GFP-positive neurons showed that they are fast spiking, nonadapting, and have large afterhyperpolarizations (AHPs), characteristic of PV-positive basket interneurons (S. Nelson and Z. J. Huang, unpublished 
data). GFP was not only detected in basket cell soma, dendrites, and axons but also in putative presynaptic boutons, which formed highly characteristic perisomatic "puncta rings" around putative pyramidal cell somata (Fig. $1 D$ ). In mature $\mathrm{G} 42$ mice, these GFP-positive boutons were also immunoreactive to GAD65, an isoform of the GABA synthetic enzyme specifically localized to mature GABAergic presynaptic terminals (Fig. 1D). Indeed, using immunoelectron microscopy, we confirmed that GFP-immunoreactive boutons were presynaptic components of symmetric synapses located on or near cell soma in adult visual cortex of G42 mice (Fig. $1 E$ ). Previous studies on the development of GABAergic synapses mostly relied on GAD65 immunohistochemistry (Huang et al., 1999). However, GAD65 expression represents enzyme localization rather than synapse structure and is developmentally regulated with a late onset of targeting to presynaptic terminals. In addition, perisomatic synapses derive from two nonoverlapping subclasses of basket interneurons, those containing Pv or CCK (Freund, 2003). The restricted GFP expression in $\mathrm{PV}$ interneurons in G42 mice therefore allows efficient and reliable characterization of the formation, maturation, and plasticity of a major class of perisomatic synapses in vivo. GFP expression in G42 mice was also prominent in the cerebellum, thalamus, hippocampus, striatum, brain stem, and other brain areas, which will be described elsewhere.

\section{Maturation of perisomatic innervation} by basket interneurons in visual cortex In the visual cortex of G42 mice, more GFP-positive neurons were found in infragranular layers 5 and 6 (Fig. $1 B$ ). Therefore, we have restricted our studies to these cortical layers. We characterized the maturation of perisomatic innervation in the visual cortex during the postnatal period from eye opening to early adulthood, when the development of visual cortical circuits is profoundly influenced by visual experience. To visualize pyramidal cell somata innervated by basket interneurons, we used NeuN immunoreactivity. NeuN is thought to be a pan-neuronal marker. However, we discovered that, under our experimental conditions (see Materials and Methods), NeuN immunoreactivity, in fact, was restricted to pyramidal neurons, but not GABAergic interneurons, in the neocortex. During postnatal development, NeuN completely colocalized with Emx-1, a pyramidal neuron-specific transcription factor (145 of 145 cells; supplemental material, available at www.jneurosci.org) (see Fig. 5), but did not colocalize with several GABAergic interneuron markers such as $\mathrm{Pv}$ (0 of 92 cells) and SOM ( 0 of 41 cells). We therefore quantified perisomatic innervation by measuring the number of GFP-labeled basket interneuron presynaptic boutons around NeuN-positive pyramidal cell somata in layers 5-6 of the visual cortex (see Materials and Methods).

Shortly after eye opening at P14, perisomatic boutons were
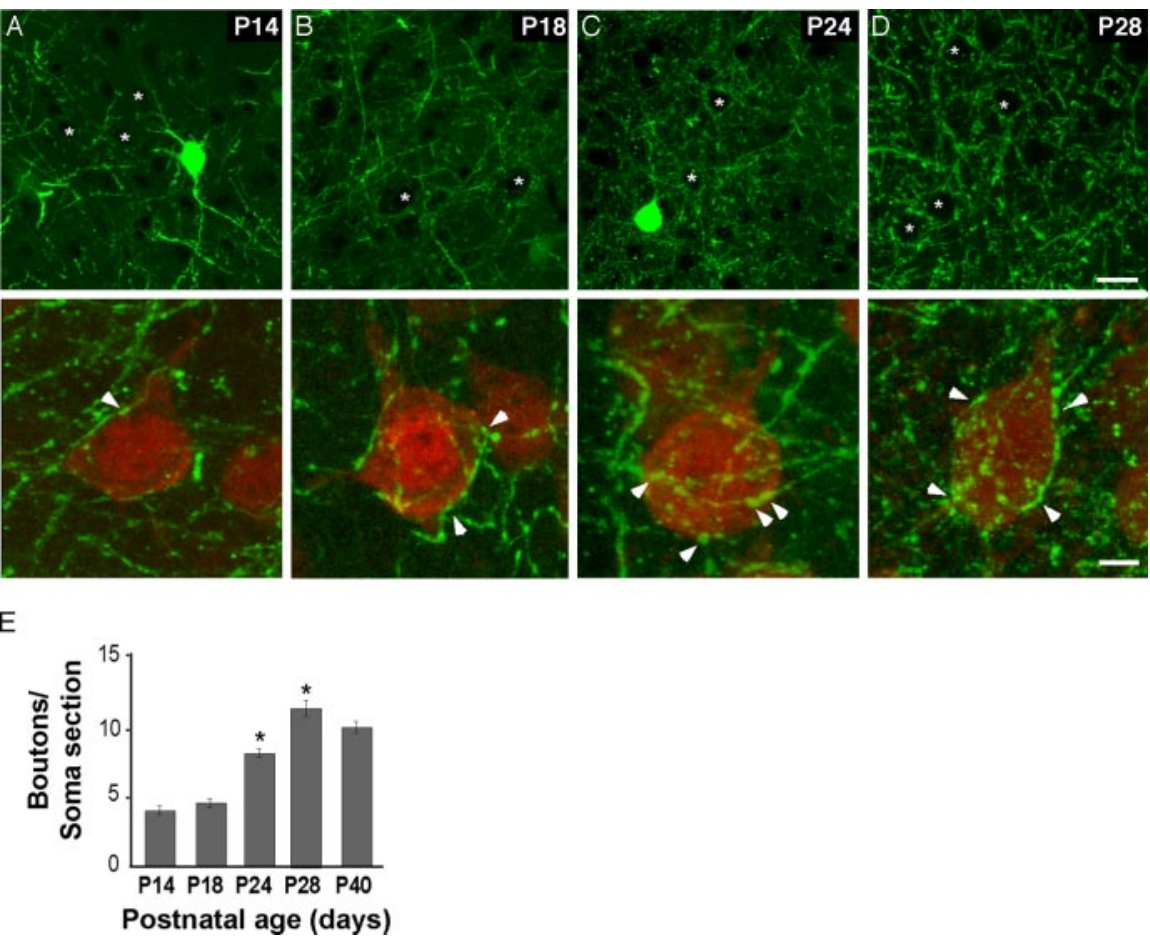

Figure 2. Prolonged postnatal maturation of perisomatic innervation by basket interneurons in primary visual cortex. $A-D$, (top), and the number of boutons around each pyramidall soma increases significantly (bottom). $D, A$ P28, highly prominent perisomatic bouton rings are observed (top), which often enclose a large portion of the pyramidal cell soma

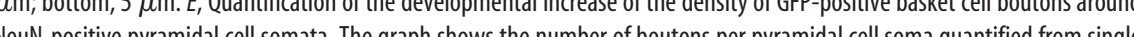
confocal sections (boutons/soma section; see Materials and Methods) at different ages. Bouton density increases significantly between P18, P24, and P28 (one-way ANOVA, post hoc Dunn's test; $p<0.05$ ).

small and poorly developed around pyramidal cell somata, although basket cell dendrites, axons, and axon terminals were prominently labeled with GFP (Fig. $2 A$ ). We quantified the number of GFP-positive boutons around pyramidal cell somata on single confocal sections (Fig. $2 E$ ) (number of boutons/soma section \pm SEM, $3.9 \pm 0.4 ; n=139$ cells; three mice; "soma/section" is an optical section of a pyramidal cell soma in a single confocal plane). There was no evidence of perisomatic bouton rings (Fig. 2 A) (asterisks mark pyramidal cell somata positions). At P18, there was a marked increase of basket axon terminal density in the neuropil and around pyramidal cell somata. However, perisomatic boutons were still poorly arranged, far from forming a complete bouton ring (Fig. $2 B, E$ ) (number of boutons/soma section $\pm \mathrm{SEM}, 4.5 \pm 0.4 ; n=131$ cells; three mice). It was not until the third postnatal week (P24) (Fig. 2C), when the number of boutons around pyramidal cell somata increased substantially (number of boutons/soma section \pm SEM, $8.2 \pm 0.5 ; n=320$ cells; five mice; one-way ANOVA, post hoc Dunn's test; $p<0.05$ ) and mature perisomatic bouton rings started to emerge (Fig. $2 C$, arrowheads). During the fourth week (P28) (Fig. 2D), basket cell presynaptic boutons continued to increase and surround pyramidal cells, until highly prominent perisomatic bouton rings 

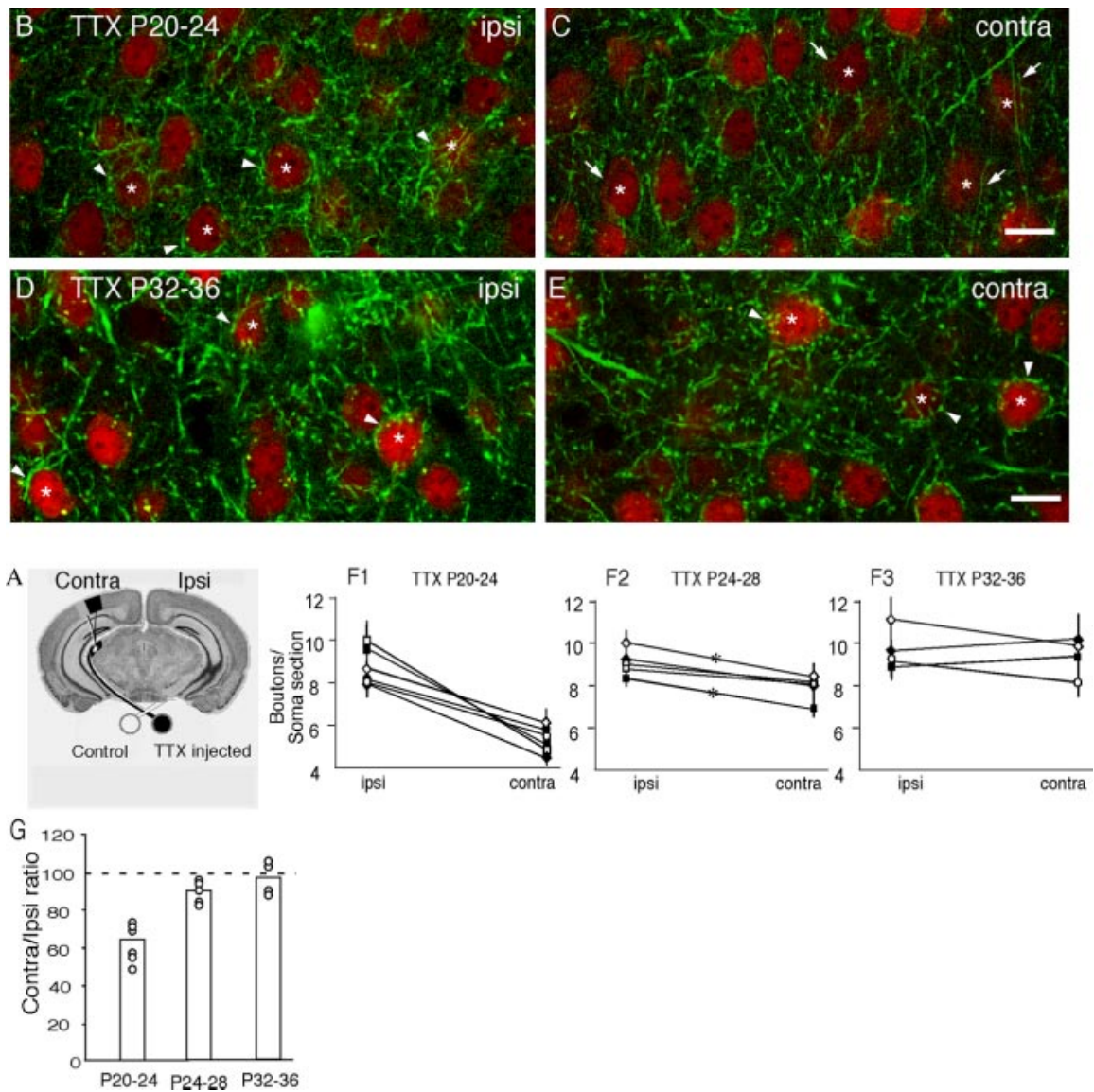

Figure 3. Intraocular TTX injection decreases the maturation of perisomatic GABAergic innervation in visual cortex during the third, but not the fifth, postnatal week. A, Diagram showing monocular TTX injection paradigm. B, C, Daily monocular TTX injection between P20 and P24 reduces perisomatic innervation of pyramidal neurons in binocular primary visual cortex. In the cortex ipsilateral to TTX injection (nondeprived; $B$ ), pyramidal cell somata (asterisks) are consistently surrounded by basket interneuron terminal branches and perisomatic bouton rings (arrowheads; note similarity to Fig. $2 C$ ). In the contralateral deprived cortex ( $C$ ), however, perisomatic innervation is significantly reduced. Many pyramidal cell somata (asterisks) are poorly surrounded by basket axon terminals and boutons (arrows), with no apparent perisomatic bouton rings. Pyramidal neurons in $B$ and ( are labeled with NeuN immunofluorescence (red). D, E, Monocular TTX injection between P32 and P36 does not affect perisomatic innervation of pyramidal neurons in the visual cortex. Both the ipsilateral $(D)$ and controlateral $(E)$ cortex show prominent perisomatic bouton rings (arrowheads) around pyramidal cell somata (red). Asterisks mark pyramidal cell soma. Scale bar, $20 \mu \mathrm{m}$. F, G, Quantification of perisomatic bouton density around pyramidal neurons in the visual cortex of mice with monocular TTX injection. F1, In the P20 - P24 injected group, the contralateral (deprived) cortex shows a significant reduction in perisomatic bouton density compared with the ipsilateral (nondeprived) cortex (Mann-Whitney $U$ test; $p<0.01$ ). F2, In the P24-P28 injected group, the contralateral (deprived) cortex shows a trend toward a reduction in perisomatic bouton density compared with the ipsilateral (nondeprived) cortex, but this reduction is significant only in two of five animals (asterisk; Mann-Whitney $U$ test; $p<0.05$ ). F3, In the P32-P36 injected group, there was no statistical difference in perisomatic bouton density between the contralateral (deprived) and the ispilateral (nondeprived) cortex (Mann-Whitney $U$ test; $p>0.4$ ). Values from the ipsilateral and contralateral cortices are shown for each animal. G, Effects of monocular TTX injection on perisomatic innervation in the contralateral (deprived) cortex normalized to ipsilateral (nondeprived) cortex. Values from each animal are represented by open circles. The average values are indicated by histogram.

formed, which often enclosed a large portion of pyramidal cell soma surface (Fig. 2D,E) (boutons/soma section \pm SEM, $11.7 \pm$ $0.9 ; n=175$ cells; three mice; one-way ANOVA, post hoc Dunn's test; $p<0.05)$. Perisomatic innervation reached a plateau in the fifth postnatal week (Fig. $2 D, E$ ) (boutons/soma section \pm SEM, $9.9 \pm 0.5 ; n=237$ cells; four mice; one-way ANOVA, post hoc Dunn's test; $p>0.05)$. Therefore, the maturation of perisomatic innervation by $\mathrm{Pv}$-positive basket interneurons in the visual cortex is a prolonged postnatal process, extending well into late juvenile and early adulthood. This time course is well correlated with the physiological enhancement of GABAergic transmission (Morales et al., 2002), suggesting that the maturation of periso- matic innervation is a component of the overall increase of GABAergic innervation in postnatal visual cortex.

\section{Intraocular TTX injection reduces perisomatic innervation in primary visual cortex during the third, but not the fifth, postnatal week}

Input from the contralateral eye dominates the sensory activation of mouse primary visual cortex. Consequently, cortical activity in one hemisphere can be significantly reduced by monocular injection of TTX (Caleo et al., 1999). To examine the role of visual experience in the maturation of perisomatic innervation, we injected 3 mM TTX daily into one eye of G42 mice from P20 to P24, P24-P28, and from P32 to P36. We then quantified and compared perisomatic innervation of layer 5 pyramidal neurons in the binocular regions of the primary visual cortex in the two hemispheres, blind to the site of TTX injection. Pyramidal cell somata were labeled by NeuN immunofluorescence. At P24, in the binocular region ipsilateral to the injected eye (nondeprived cortex), perisomatic innervation appeared normal. Pyramidal cell somata were consistently surrounded by perisomatic bouton rings (Fig. 3B) (note similarity to Fig. 2C). Perisomatic bouton density was not significantly different from that in the cortex of uninjected, age-matched control mice (number of boutons/soma section \pm SEM, $8.9 \pm 0.6$ in the ipsilateral cortex of TTX injected mice; $n=3$; number of boutons/ soma section \pm SEM, $8.2 \pm 0.5$ in the cortex of age-matched controls; $n=5$ mice; Mann-Whitney $U$ test; $p>0.05)$. In the binocular region contralateral to the TTXtreated eye (deprived cortex), however, perisomatic innervation appeared significantly reduced (Fig. 3C). Many pyramidal cell somata were not surrounded by perisomatic rings. There was on an average a $36 \%$ reduction in perisomatic bouton density in the deprived cortex compared with those in the nondeprived cortex (Fig. $3 F 1, G)(n=6$ mice; contralateral/ipsilateral ratio: $48,73,59,75,74$, and $57 \%$, re-

spectively; Mann-Whitney $U$ test; $p<0.01$ for each animal). GFP expression in basket cell somata, dendrite, and axons in the deprived cortex did not appear to be affected (Fig. 3). Buffer injection alone did not reduce perisomatic bouton density in the binocular region of the contralateral cortex compared with that in the ipsilateral cortex (images not shown; $n=2$ mice; contralateral/ipsilateral ratio: 102 and 93\%, respectively; Mann-Whitney $U$ test; $p>0.4$ in both cases).

The effect of monocular TTX injection from P32 to P36 was very different. In the binocular region ipsilateral to TTX injection (nondeprived cortex), perisomatic innervation was comparable 
with age-matched controls (Fig. 3D) (see also Fig. 2D). Perisomatic bouton rings of the basket interneurons were distinct and completely surrounded pyramidal cell somata. In the binocular region contralateral to TTX injection (deprived cortex), the overall pattern of basket cell axons, boutons, and perisomatic innervation were indistinguishable from the nondeprived cortex (Fig. $3 E)$. There was no significant difference in perisomatic bouton density between the two hemispheres (Fig. $3 F 3, G)(n=4$ mice; contralateral/ipsilateral ratio: $106,103,90$, and $88 \%$, respectively; Mann-Whitney $U$ test; $p>0.4$ in all cases). Therefore, the reduction of perisomatic innervation in the primary visual cortex by monocular TTX injection was significant in the third week but absent in the fifth week.

To better define the time window during which perisomatic innervation is sensitive to sensory experience, we injected TTX in a group of mice between P24 and P28. TTX treatment between P24 and P28 was less effective than between P20 and P24 but more effective than between $\mathrm{P} 32$ and P36. In the binocular region contralateral to TTX injection (deprived cortex), we observed a trend toward a reduction in the perisomatic bouton density compared with those in the ispilateral cortex, but this difference was statistically significant $(p<0.05)$ only in two of five animals (Fig. $3 F 2, G)(n=5$ mice; contralateral/ipsilateral ratio: $96,94,90,85$, and $83 \%$, respectively; Mann-Whitney $U$ test; $p<0.05$ only for last two animals). These results suggest the presence of a critical period between the third and the fourth postnatal week, when perisomatic GABAergic innervation in the primary visual cortex can be significantly modified by sensory experience.

\section{Development of basket interneurons and perisomatic synapses in cortical organotypic cultures visualized at single-cell resolution}

Because most GABAergic interneurons in infragranular layers do not receive direct thalamic inputs, visual experience most likely influences the maturation of GABAergic synapse by regulating mechanisms intrinsic to cortex, such as the level and pattern of intracortical neural activity. To understand whether and how neuronal activity regulates maturation of perisomatic synapses, we established an organotypic culture system that allows easy manipulation of neural activity. We first examined whether, and to what extent, maturation of perisomatic innervation can proceed in cortical organotypic cultures, in the absence of thalamic inputs.

To characterize the cellular process of perisomatic innervation at high resolution, we developed a method to visualize perisomatic synapses from individual basket interneurons. We used BAC engineering to identify transcription promoter segments that confer basket cell-specific gene expression in organotypic cultures of the visual cortex through biolistic transfection. Using gap repair-mediated homologous recombination (Lee et al., 2001) (see Materials and Methods), we subcloned a segment of DNA from our modified GAD67-GFP BAC clone (Fig. 4A), which included a $10 \mathrm{~kb}$ region of the GAD67 promoter and the GFP coding region, into a mammalian expression vector backbone. This construct, $\mathrm{P}_{\mathrm{G} 67}-\mathrm{GFP}$ (Fig. 4A), conferred basket interneuron-restricted gene expression in cortical slice cultures. Transfected GFP-positive neurons were predominantly interneurons immunopositive for $\mathrm{Pv}$ (Fig. 4B) (PV positive; 27 of 30 cells) but negative for SOM (SOM positive; 0 of 28 cells) and CR immunoreactivity (CR positive; 0 of 25 cells). Pyramidal neurons were occasionally transfected but could be easily distinguished based on standard morphological criteria. Importantly, transfected GFP-positive neurons were confirmed by patch-clamp recording to show fast, nonadapting spiking, and large AHP, which are characteristic of basket interneurons (Fig. 4C). This method thus allowed us to characterize the development of basket interneuron axons and synapses at single-cell resolution.

Visual cortical slices were prepared from P3 mouse pups and cultured for up to 5 weeks in vitro. Slices were transfected biolistically with $\mathrm{P}_{\mathrm{G} 67}$-GFP usually 3-4 d before confocal imaging. At equivalent $\mathrm{P} 5(\mathrm{EP} 5=\mathrm{P} 2+3 \mathrm{~d}$ in vitro $)$, transfected interneurons were highly immature, with small and simple dendrites. Their axons were also very simple, with only two to three branches and no visible varicosities (supplemental material, available at www. jneurosci.org). The overall morphology of basket cells matured dramatically over the next 3 weeks in vitro. At EP11 (P3 plus $8 \mathrm{~d}$ in vitro) (Fig. $4 D$ ), basket interneurons displayed relatively simple dendritic trees and small axon arbors. Although basket cell axons had more branches than those at EP5, they were still sparse and smooth, with only a very limited number of small varicosities. At EP18 (P3 plus $15 \mathrm{~d}$ in vitro) (Fig. $4 E$ ), the dendrite and axon arbors reached near mature size. The axon arbors were branched extensively, yet axon terminals were still immature, with many filopodial protrusions (P18) (Fig. $4 E$, arrow). The punctate varicosities along axons, highly indicative of presynaptic boutons, were distinct and numerous. At EP24 (P3 plus $21 \mathrm{~d}$ in vitro) (Fig. $4 F$ ), basket axons were branched extensively and very dense. The most prominent feature at this stage was the appearance of highly distinct "terminal forks," two or three end branches covered with prominent and numerous regularly spaced boutons, presumably surrounding a pyramidal cell soma (Fig. $4 F$, asterisk and arrowheads). At EP28 (P3 plus 25 d in vitro) (Fig. 4G), basket cell axon terminal forks became even more distinct and complex and contained more boutons (asterisk and arrowheads). GFP-positive boutons, but not the thin axons between them, completely colocalized with GAD65 by EP18 (the earliest time we have examined such colocalization) (Fig. $4 \mathrm{H}$ shows data at EP28), suggesting that they contained GABAergic synaptic transmission machinery. Finally, immunoelectron microscopy confirmed that these GFP-immunoreactive boutons were indeed the presynaptic component of symmetric synapses (Fig. 4I). These results suggest that the highly elaborate axonal arbors of basket interneurons and their distinctive terminal branches develop in cortical slice cultures.

\section{Perisomatic synapse formation proceeds in organotypic cultures with a time course similar to that of the maturation of perisomatic innervation in visual cortex}

To efficiently identify pyramidal cell somata and quantify perisomatic synapses around them, we used a strain of knock-in mouse in which a DNA segment containing a nuclear-targeted lacZ gene, followed by ires-Cre, was inserted into the emx-1 coding region (Guo et al., 2000). Emx-1 is a helix-loop-helix transcription factor with expression restricted to pyramidal neurons in postnatal neocortex and hippocampus (Chan et al., 2001). Within intact visual cortex, the expression of emx-lacZ shows a distinct border between layers 4 and 5, reflecting differences of pyramidal cell densities in supragranular and infragranular layers (Chan et al., 2001). This layer 4 to layer 5 border was well preserved even after 5 weeks in slice cultures, which allowed us to select neurons in layer 5 for imaging (Fig. 5A). Basket interneurons were transfected using biolistics with $\mathrm{P}_{\mathrm{G} 67}$-GFP and imaged in a background of red pyramidal nuclei labeled by immunofluorescence with an antibody to $\beta$-gal (Fig. 5A). This antibody gave substantially improved tissue penetration compared with antibodies to $\mathrm{NeuN}$ in slice cultures (data not shown). Figure $5 B$ shows the axon arbors of a single basket cell at EP22 covering a cortical 

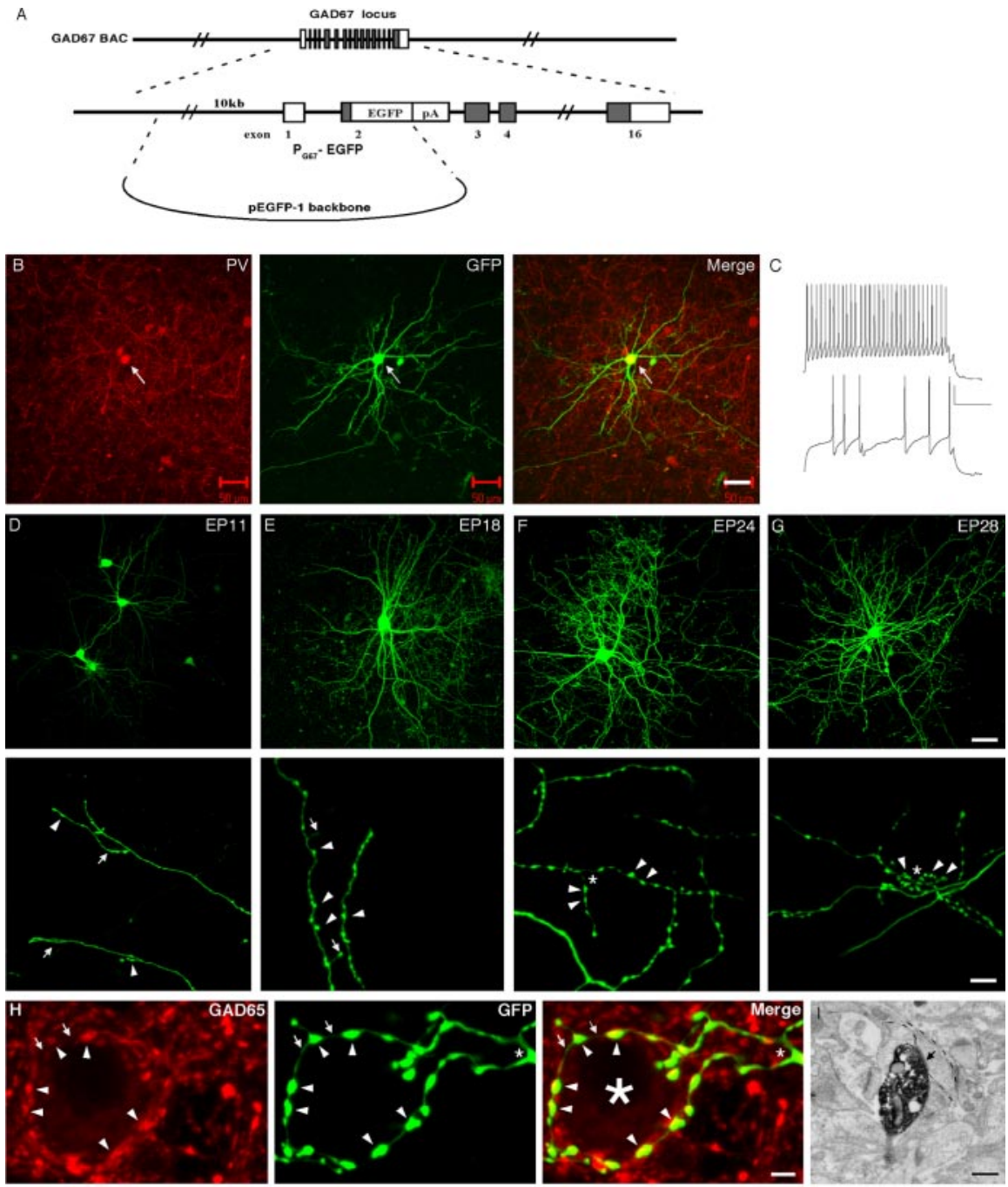

Figure 4. High-resolution characterization of the development of basket interneurons in organotypic cultures. $A, A$ DNA segment containing a $10 \mathrm{~kb}$ region of the GAD67 promoter $\left(\mathrm{P}_{\mathrm{G67}}\right)$ followed by the EGFP cassette from our modified GAD67-GFP BAC clone (see Fig. $1 A$ ) was taken to replace the EGFP coding region in the expression vector pEGFP-1 (Clontech), through gap repair-mediated $B A C$ engineering. $B$, Biolistic transfection of $P_{G 67}-G F P$ directs GFP expression in Pv-positive GABA interneurons in cortical organotypic cultures. The arrow points to a GFP-expressing interneuron (middle), which is also positive for Pv immunofluorescence (red in left panel). Scale bar, $50 \mu \mathrm{m}$. C, Whole-cell current-clamp recording shows that GFP-expressing neurons are fast spiking, nonadapting, and have large AHPs. Bottom trace, 400 pA current step; top trace, 650 pA current step. Calibration: 20 $\mathrm{mV}, 100 \mathrm{msec}$. Synaptic activity is evident, as expected in organotypic cultures (Echevarria and Albus, 2000). D-G, Basket interneurons develop their elaborate dendritic and axon arbors and synaptic boutons in vitro. Higher-magnification images in the bottom panels show details of terminal branches and presynaptic boutons. D, At EP11, basket interneurons display relatively simple dendritic trees and sparse axon branches (arrows; bottom) with very few boutons (arrowheads; bottom). E, At EP18, the dendrite and axon arbors appear to have reached near mature sizes. The axons are branched extensively, yet the axon terminals are still rather immature, characterized by filopodial-like protrusions (arrow; bottom), in addition to distinct boutons (arrowheads; bottom). F, At EP24, axon branches are more exuberant, and highly distinct terminal forks emerge (asterisk; bottom) with strings of synaptic boutons (arrowheads; bottom). G, At EP28, axon terminal forks become more complex (asterisk; bottom), with larger and more boutons (arrowheads; bottom). Scale bars: top, $50 \mu \mathrm{m}$; bottom, $5 \mu \mathrm{m}$. H, A basket cell axon terminal fork (asterisk; middle) surrounds a cell soma (large asterisk; right) with synaptic boutons positive for GAD65 immunoreactivity (red; arrowheads) at EP28. Note that the thin axon segments between boutons are devoid of GAD65 immunoreactivity (arrows). Scale bar, $2 \mu \mathrm{m}$. I, A basket bouton containing dark GFP precipitate was confirmed to be the presynaptic terminal of a symmetric synapse (arrow) by immunoelectron microscopy. The postsynaptic dendritic target is outlined by segmented lines. Scale bar, $0.7 \mu \mathrm{m}$.

domain containing a large number of pyramidal cell somata. Many pyramidal cell somata were situated perfectly between the end branches of basket axon terminal forks, decorated by strings of boutons (Fig. 5D, arrowheads). This distinctive "ball on a fork" structure was highly consistent and allowed us to set a morphological criterion for perisomatic synapses at single-cell res-

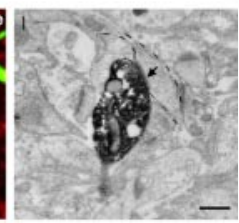

olution and to devise a Reverse ThreeDimensional Sholl analysis for quantification: we define those basket cell boutons located within a $7 \mu \mathrm{m}$ sphere from the center of a pyramidal cell nucleus as perisomatic synapses (see Materials and Methods). This analysis gives an estimate, but not an exact count, of the number of perisomatic synapses and the complexity of basket axon terminals around a pyramidal cell soma.

Using Reverse Three-Dimensional Sholl, we then characterized the formation and maturation of perisomatic synapses in slice cultures at different developmental stages. At present, we do not know the time and subcellular location of the initial contact from basket axons to pyramidal neurons. By EP14, basket cell axons coursed through groups of pyramidal cells with limited branching and were already reliably found around pyramidal cell somata (Fig. $6 B, C$ ). These axons had no additional branches around pyramidal cell soma and frequently contained only one or two boutons near soma (Fig. 6A-C,N) (number of boutons/soma \pm SEM, $2.6 \pm$ $0.3 ; n=41$ pyramidal cell somata from $n=7$ basket cells). At EP18, basket cell axon arbors became more complex, had more extensive branches, and contacted more pyramidal cell somata; but axon branches around each pyramidal cell soma were not significantly different from those at EP14 in bouton number and branch complexity (Fig. 6D-F,N,P) (boutons/ soma \pm SEM, $3.4 \pm 0.4 ; n=31$ pyramidal cell somata from $n=6$ basket cells). Within the next 4-5 d, basket cell axons extended one or more end branches around a pyramidal cell soma, forming the characteristic terminal fork (EP24) (Fig. $6 G-I)$. This was indicated by a marked increase in the fraction of pyramidal cell somata surrounded by two or more basket cell axon end branches. This was quantified as a higher number of intersections between Sholl spheres of these pyramidal cells and the surrounding basket axon branches compared with those pyramidal cells from EP18 and earlier (see Materials and Methods) (Fig. 6P) (Kruskal-Wallis one-way ANOVA; $p<0.05)$. Bouton density around pyramidal cell somata also increased significantly (EP24) (Fig. 6G-I,N) (boutons/soma \pm SEM, $7.4 \pm 0.7 ; n=29$ pyramidal cell somata from $n=6$ basket cells; one-way ANOVA, post hoc Dunn's test; $p<0.05$ ), with larger boutons size (Fig. $6 \mathrm{~N}, \mathrm{O}$ ) (average bouton diameter \pm SEM, $0.77 \pm 0.02 \mu \mathrm{m}$ at EP24 compared with $0.41 \pm 0.01 \mu \mathrm{m}$ at EP18; one-way ANOVA, post hoc Dunn's test; $p<0.05)$. From EP24 to EP28, there was an additional increase of bouton density around pyramidal cell soma (Fig. $6 J-L, N$ ) (boutons/soma \pm 
SEM, $11 \pm 1 ; n=50$ pyramidal cell somata from $n=7$ basket cells; one-way ANOVA, post hoc Dunn's test; $p<0.05)$. In contrast, there were no significant changes in the structure of terminal forks (Fig. $6 J-L, P$ ) $\left(\chi^{2}\right.$ test; $\left.p=0.25\right)$. Therefore, the formation of perisomatic synapses proceeded in organotypic cultures and was characterized by a stereotyped sequence of morphogenic events that included the growth and branching of basket cell axons toward pyramidal cell soma as early as EP14, proliferation of presynaptic boutons and extension of additional terminal axon branches between EP18 and EP24, and additional proliferation of boutons around pyramidal cell somata after EP24 (summarized in Fig. 6M). Perisomatic synapse formation is a distinct and specific feature of basket interneurons rather than a default state of synapse formation in slice culture, because the SOM-containing class of GABAergic interneurons avoided pyramidal cell somata and targeted their boutons onto dendrites and spines in our slice cultures (data not shown).

Taken together, these results suggest that the formation of highly characteristic perisomatic synapses by basket interneurons are mostly directed by mechanisms intrinsic to local cortical circuits and can proceed, to a substantial extent, in the absence of thalamic input. On the other hand, our visual deprivation experiments clearly indicate a role of sensory input in the maturation of perisomatic innervation in vivo. The link between cortical intrinsic and experience-dependent mechanisms may lie in the regulation of neuronal activity in cortical circuits. Indeed, cortical organotypic cultures generate spontaneous waves of neuronal activity as a result of extensive local synaptic connectivity and transmission (Klostermann and Wahle, 1999; Echevarria and Albus, 2000). Therefore, we next examined whether and how alterations of neuronal spiking activity influences the formation of perisomatic synapses.

\section{Neuronal spiking activity regulates the formation of} perisomatic synapses in cortical organotypic cultures Because we have shown that the formation of perisomatic synapses involved a stereotyped sequence of morphogenic events including the extension of basket cell axon terminal forks and proliferation and enlargement of boutons around pyramidal cell soma, each within a defined time window (Fig. 6), we tested whether the progression of each of these morphogenic events was influenced by changes in the level of neuronal spiking activity. We included $1 \mu \mathrm{M}$ TTX in our culture medium from EP14 to EP18, EP18-EP24, and EP24-EP28 to reduce Na- dependent neuronal spiking. Although TTX-insensitive sodium channels exist in neocortical neurons (Jeong et al., 2000), TTX treatment has been shown to substantially reduce spiking activity (Echevarria and Albus, 2000). In all TTX-treated groups, we did not notice gross alterations in axonal arbor size and morphology of basket interneurons compared with those in control groups (Fig. $7 A, E, I)$ (compare with Fig. 6). The same treatment did not alter their dendritic morphologies during these time windows (Jin et al., 2003). Therefore, the basic cellular architecture of basket interneurons does not appear to be grossly altered by changes in TTX-sensitive activity levels after the second week in slice cultures. We then quantified perisomatic synapse formation around
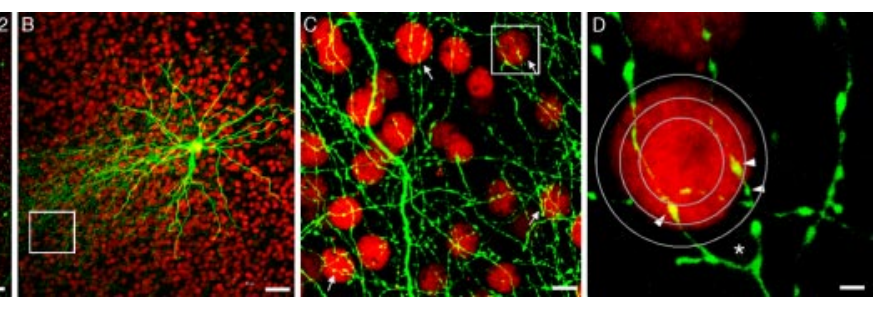

Figure 5. Visualization of perisomatic innervation and perisomatic synapses by a single basket interneuron with its pyramidal

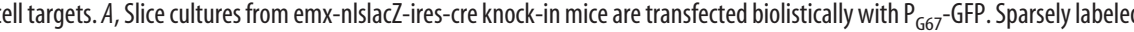
cence (red xon arbor of a single basket interneuron (green). C, Higher-magnification view of the region marked in $B$. Many pyramidal cell between the two terminal branches (supplemental material, available at www.jneurosci.org). Sholl spheres for Reverse ThreeDimensional Sholl analysis are shown (see Materials and Methods). Scale bars: $A, 100 \mu \mathrm{m} ; B, 50 \mu \mathrm{m} ; C, 10 \mu \mathrm{m} ; D, 2 \mu \mathrm{m}$.

layer 5 pyramidal neurons after TTX treatment and compared with those in control conditions.

Between EP14 and EP18, basket cell axons from control neurons were still extending their branches and contacting more pyramidal cell somata. During this period, we did not find significant differences between the TTX-treated and control groups in terminal branch complexity (Fig. 7D) (quantification in Fig. $8 C$ ) ( $\chi^{2}$ test; $p=0.2$; TTX treated, $n=34$ pyramidal cells from $n=7$ basket cells; EP18 control, $n=32$ pyramidal cells from $n=6$ basket cells), bouton size (Fig. $8 B)(0.40 \pm 0.01 \mu \mathrm{m}$ for EP18 TTX vs $0.41 \pm 0.01 \mu \mathrm{m}$ for EP 18 control; Mann-Whitney $U$ test; $p=0.5$ ), and bouton density around pyramidal cell somata (Fig. $8 \mathrm{~A}$ ) (boutons/soma $\pm \mathrm{SEM}, 3.0 \pm 0.4$ for EP18 TTX vs $3.4 \pm 0.4$ for EP18 control; Mann-Whitney $U$ test; $p=0.5$ ). These results suggest that either the initial growth of basket cell axons toward pyramidal cell soma does not require spiking activity or that the initial contacts formed at or before EP14 can be maintained with a reduced level of spiking activity.

In contrast, the extension of additional terminal branches around pyramidal cell soma was almost completely blocked by TTX treatment between EP18 and EP24 (Fig. 7G,H). The fine branches of basket axons appeared thinner and more wavy (compare Figs. $6 G, H, 7 F, G$ ). Some basket axon terminal branches, rather than surrounding pyramidal cell somata as in the control group, ran tangentially to pyramidal cell somata and appeared to be turning away from them (Fig. 7, compare H1, H4). This was reflected in the fact that terminal branch complexity in the EP18EP24 TTX-treated slice was notably less than not only those of E24 but also those of the EP18 control group (Fig. 8D) (note the absence of pyramidal cell classes showing the higher number of Sholl sphere intersections with basket axons; $\chi^{2}$ test; $p<0.001$ ). In addition, the increase of bouton density around pyramidal cell somata between EP18 and EP24 was also significantly blocked by TTX treatment (Figs. 7H1-H4, 8A) (boutons/soma \pm SEM, $3.0 \pm 0.3$ for EP24 TTX vs $7.4 \pm 0.7$ for EP24 control; MannWhitney $U$ test; $p<0.001$; TTX treated, $n=35$ pyramidal cells from $n=7$ basket cells; EP24 control, $n=29$ pyramidal cells from $n=6$ basket cells). Finally, average bouton size was also reduced by TTX treatment (bouton diameter \pm SEM, $0.45 \pm 0.01$ $\mu \mathrm{m}$ for EP24 TTX compared with $0.77 \pm 0.02 \mu \mathrm{m}$ for EP24 control; Mann-Whitney $U$ test; $p<0.001)$. These results suggest that both the extension of additional basket axon terminal branches and proliferation of boutons around pyramidal cell somata are regulated by changes in the levels of TTX-sensitive 

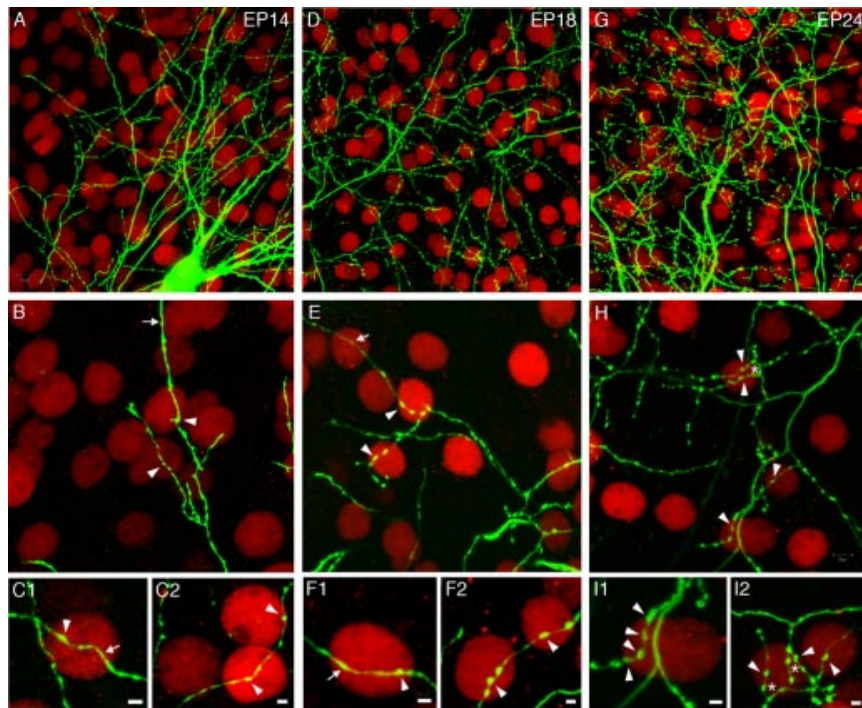

M
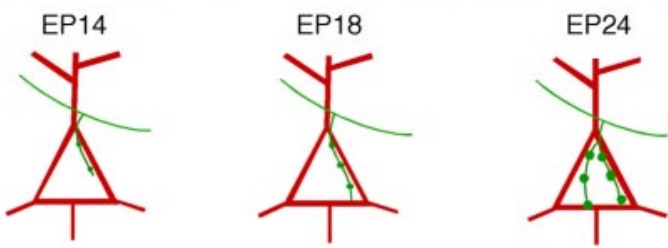

N
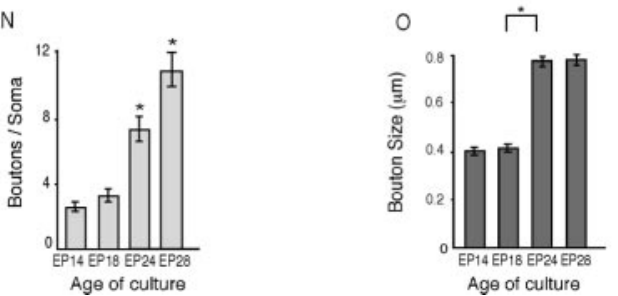

P

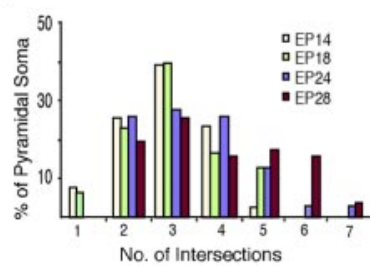

Figure 6. Formation of perisomatic synapses proceeds in cortical organotypic cultures. A-C,AtEP14, many axon branches have reached and surrounded pyramidal cell somata but contain only one or two putative boutons around each soma (arrowheads). Note long segment of axons devoid of boutons (arrow). D-F, At EP18, more pyramidal cell somata are likely innervated (D), but basket axon terminal branch complexity and bouton density around each pyramidal cell soma (arrowheads in $E$ and $F$ ) are similar to those at EP14. G-I, At EP24, one or more axonal branches extend around a pyramidal cell soma to form a terminal fork (asterisk), along with an increase in the number and size of boutons (arrowheads in $\mathrm{H}$ and $/$ ). $J-L, A t E P 28$, there is an additional increase in bouton number (arrowheads) within terminal forks, which in some cases resemble a basket (asterisk). Scale bar: (top) A, D, G, J, 15 $\mu \mathrm{m}$; (middle) $B, E, H, K, 10 \mu \mathrm{m}$; (bottom) $C, F, I, L, 2 \mu \mathrm{m}$. M, A schematic summarizing the stereotyped process of perisomatic synapse formation. $N$, Quantification of the developmental increase of basket cell presynaptic boutons density around pyramidal cell somata. The bouton number around each pyramidal cell soma is quantified by Reverse Three-Dimensional Sholl analysis within a $7 \mu \mathrm{m}$ Sholl sphere from the center of its nucleus. Bouton density increases significantly between EP18 and EP28 (1-way ANOVA, post hoc Dunn's test; $p<0.05$ ). 0, Average bouton diameter, measured perpendicular to the axon, at different developmental ages. Bouton size increases significantly between EP18 and EP24 (one-way ANOVA, post hoc Dunn's test; $p<0.05$ ). $P$, Developmental increase of basket axon terminal branch complexity around pyramidal cell somata. Pyramidal cells at different ages are grouped according to the average number of intersections between a $7 \mu \mathrm{m}$ Sholl sphere from the center of their nuclei and basket axon branches surrounding them. At EP24 and EP28, pyramidal cell somata are surrounded by more complex terminal branches than cells from EP18 and EP14, as indicated by the appearance of pyramidal cell groups showing a higher number of intersections.

neuronal activity. TTX treatment did not result in pyramidal cell degeneration because the density of pyramidal cells in TTXtreated cultures was identical to that of control cultures (number of pyramidal cell somata/field, $43.3 \pm 0.9$ for EP24 TTX vs $45.8 \pm$ 0.9 for EP24 control; Mann-Whitney $U$ test; $p=0.12$; see Materials and Methods).

From EP24 to EP28, there was no difference in the complexity of basket axon terminal branches around pyramidal cell somata between the TTX-treated group and either the EP24 or EP28 control group (Fig. $7 K, L)$ (quantified in Fig. $8 E)\left(\chi^{2}\right.$ test; $p=0.9$;
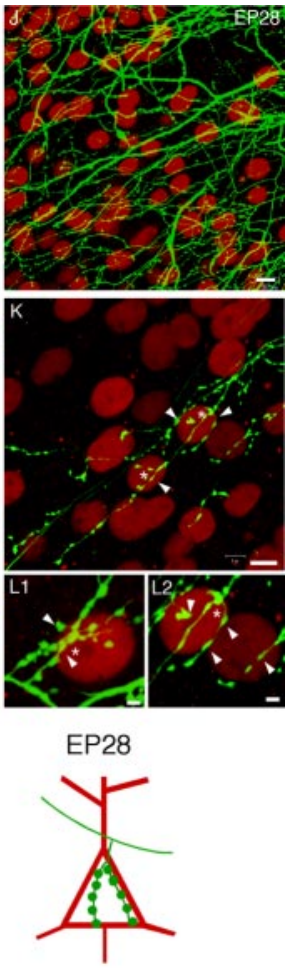

TTX treated, $n=36$ pyramidal neurons from $n=7$ basket cells; EP28 control, $n=$ 50 pyramidal cells from $n=7$ basket cells). The average bouton size was also not effected by TTX treatment (bouton diameter \pm SEM, $0.76 \pm 0.02 \mu \mathrm{m}$ for EP28 TTX vs $0.78 \pm 0.02 \mu \mathrm{m}$ for EP28 control; Man$\mathrm{n}$-Whitney $U$ test; $p=0.6)$. In contrast, additional proliferation of basket cell presynaptic boutons around pyramidal cell somata during this period was again blocked by TTX treatment (Fig. 7L1-L4) (boutons/soma \pm SEM, $7.8 \pm 0.1$ for EP28 TTX vs $11 \pm 1$ for EP28 control; MannWhitney $U$ test; $p<0.001)$. These data suggest that basket axon terminal forks, once formed, can be maintained despite reduced spiking activity. The additional proliferation of basket cell presynaptic boutons around pyramidal cell soma, on the other hand, continued to be regulated by the levels of TTX-sensitive neuronal activity during the fourth week in slice culture.

Taken together, our results indicate that although the formation of perisomatic synapses around individual pyramidal neurons can proceed in the absence of thalamic input, it is profoundly influenced by the levels of neuronal activity within the organotypic culture. TTX-sensitive neuronal activity regulates the extension of basket axon terminal branches between EP18 and EP24 and therefore influences the progression and time course of perisomatic synapse formation. In addition, neuronal activity continuously regulates the density of perisomatic boutons around pyramidal neurons between EP18 and EP28 and therefore influences the maturation and pattern of perisomatic innervation among pyramidal neurons. Because the level and pattern of activity within intact cortex is strongly regulated by thalamic and sensory input, visual experience can have a significant influence in the maturation and pattern of perisomatic innervation in the primary visual cortex.

\section{Discussion}

GABAergic inhibition directed toward the perisomatic region is particularly effective in controlling the excitability and output of a pyramidal neuron and has been implicated in the generation and entrainment of oscillatory activity patterns among populations of pyramidal neurons (Miles et al., 1996; Freund, 2003; Klausberger et al., 2003). Therefore, appropriate development and regulation of perisomatic innervation can have a profound impact on receptive field properties and functional architecture of neuronal circuits in the visual cortex.

The development of perisomatic innervation in rodent visual cortex has thus far been inferred from the expression and synaptic localization of GABA synthetic enzymes (Huang et al., 1999). 
By combining BAC transgenic reporter mice that label a defined class of perisomatic synapses, we were able to efficiently visualize and quantify perisomatic innervation in the primary visual cortex. In addition, using a cell type-specific promoter and biolistic transfection, we were able to label perisomatic synapses of single basket interneurons in organotypic cultures. These experimental systems allow us to distinguish and also relate the role of cortical intrinsic and experience-dependent mechanisms in the development of perisomatic innervation in the visual cortex. Here, we show that the formation and proliferation of the characteristic perisomatic synapses around individual pyramidal neurons was a stereotyped process that can proceed in the absence of thalamic input, but is strongly regulated by the levels of neuronal activity within cortical circuits. In contrast, maturation of perisomatic innervation in the primary visual cortex extends from eye opening well into early adulthood and is significantly retarded by visual deprivation during a restricted postnatal time window. Taken together, our results suggest that although the formation of perisomatic synapses around individual pyramidal neurons can be primarily driven by mechanisms intrinsic to the cortex, the maturation and pattern of perisomatic innervation in the visual cortex is regulated by sensory experience during a critical period, likely through regulating the level and pattern of neuronal activity in cortical circuits.

Formation of perisomatic synapses is intrinsic to cortical circuits

Given the prolonged postnatal maturation of perisomatic innervation in the visual cortex after eye opening, one might expect the development of basket interneurons and perisomatic synapses to be severely retarded in the absence thalamic input. However, we found that highly elaborate and distinct morphology of axon arbors of basket interneurons developed in organotypic cultures, resembling those reconstructed from mature visual cortex in vivo (Tamas et al., 1997; Wang et al., 2002). In addition, the formation of highly characteristic features of perisomatic synapses, multiple basket axon terminals with strings of large boutons clustered around pyramidal cell soma, also proceeded in organotypic cultures (Di Cristo et al., 2004). Furthermore, even the time course of perisomatic synapse formation in organotypic culture was comparable with that of the overall maturation of perisomatic innervation in the visual cortex. Taken together, these results suggest that, once basket interneurons have migrated to their appropriate cortical area by the time of organotypic culture preparation (at P3), the subsequent
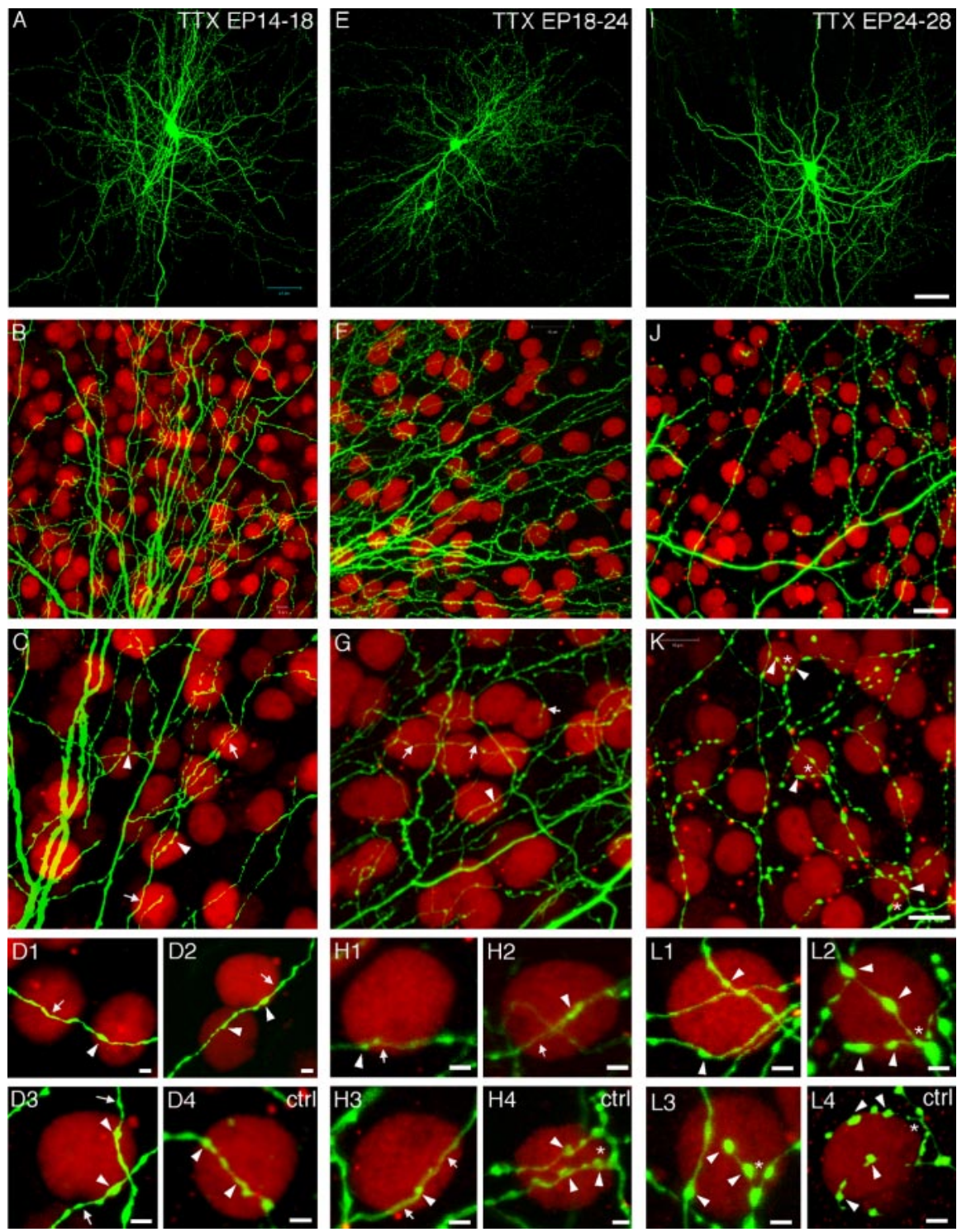

Figure 7. Formation of perisomatic synapses is regulated by neuronal spiking activity within cortical organotypic culture. $A-D$ TTX treatment from EP14 to E18 does not significantly affect the maintenance of already formed perisomatic synapses. $A, B$, Overall axon arbor and major axon branches of TTX-treated basket cells are very similar to age-matched controls (compare with Figs. $4 E, 6 D, E$ ). In addition, pyramidal cell somata are usually contacted by a single basket axon branch (arrows) containing only a few boutons (arrowheads) from TTX-treated slices (C, D1-D3), which is indistinguishable from control slices (D4). E-H, TTX treatment from EP18 to EP24 prevents the progression of perisomatic synapse formation. The overall axon arbor morphology $(E)$ was not notably affected by TTX treatment compared with age-matched controls (see Figs. 4E, 6G). However, TTX-treated basket cell axons (arrows in $G$ and $H$ ) appear more wavy, do not extend as many terminal branches, and appear to have fewer boutons (arrowheads) around pyramidal cell somata $(H 1-H 3)$ compared with the control group ( $H 4$; asterisk represents terminal fork). I-L, TTX treatment from EP24 to EP28 does not affect the already established terminal forks but prevents the additional increase of bouton density around pyramidal cell somata. The overall axon arbor morphology $(I)$ was not notably affected by TTX treatment compared with age-matched controls (see Figs. 4G, $6 \mathrm{~J}$ ). Basket axons terminal forks are present around pyramidal cell soma ( $K$, $L 1-L 3$; asterisk) with distinct boutons (arrowhead), similar to the age-matched control (L4). However, bouton density around pyramidal cell soma appears to be lower compared with the control group (quantified in Fig. 8A). Scale bars: $A, E, I, 50 \mu \mathrm{m} ; B, F$, $J, 30 \mu \mathrm{m} ; C, G, K, 15 \mu \mathrm{m} ; D, H, L, 2 \mu \mathrm{m}$.

process of axonal growth, branching, and formation of perisomatic synapses can be driven, to a substantial extent, by molecular cues and neuronal activities within local cortical circuits. Consistent with our results, there is also close parallel between the development of GABAergic synaptic transmission in organotypic cultures and acute slices of hippocampus at equivalent ages (De Simoni et al., 2003). These results contrast those obtained from dissociated neuronal cultures, in which a variety of morphologi- 

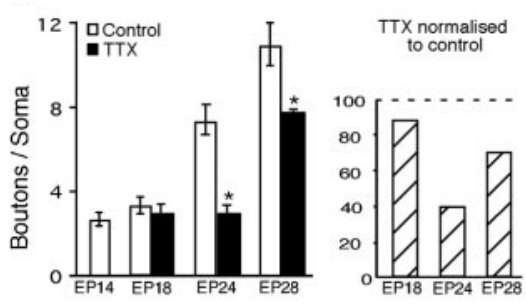

D1
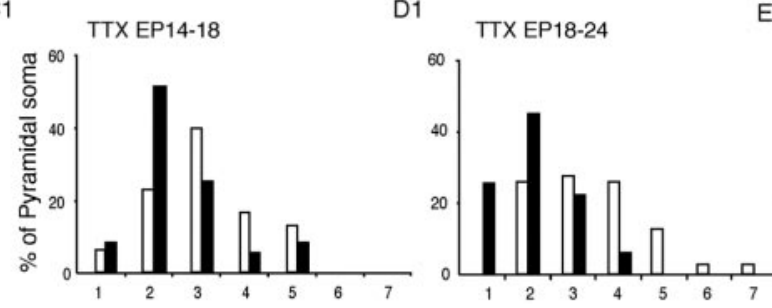

E1

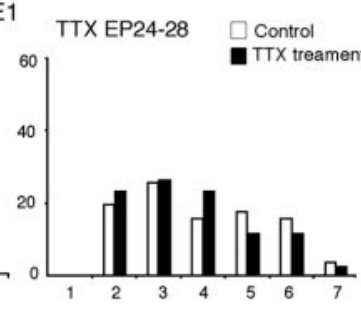
Number of intersections

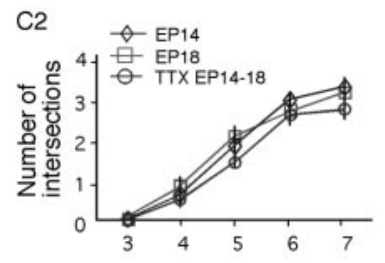

D2

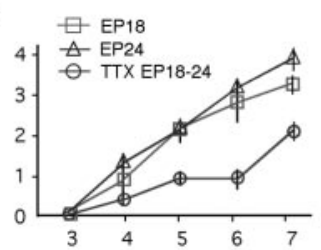

E2

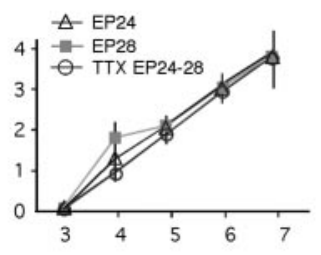

Distance from center of Pyramidal Nuclei $(\mu \mathrm{m})$

Figure 8. Quantification of activity-dependent maturation of perisomatic innervation in cortical organotypic culture. A, TTX treatment between EP18 and EP24 and EP24 and EP28 prevents the increase of bouton density around pyramidal cell soma (Mann-Whitney $U$ test; $p<0.001$ ). Right, Effects of TTX treatment normalized to age-matched control. $B$, The increase of basket axon bouton size between EP18 and EP2 4 is prevented by TTX treatment (Mann-Whitney $U$ test; $p<0.001$ ). Right, Effects of TTX treatment normalized to age-matched control. $C-E$, Reverse Three-Dimension Sholl analysis of basket axon terminal complexity around pyramidal cell soma in TTX-treated slices compared with age-matched controls. C1-E1, Pyramidal cells are grouped according to the average number of intersections between a $7 \mu \mathrm{m}$ Sholl sphere from the center of their nuclei and basket axon branches surrounding them. The developmental increase in the percentage of pyramidal cell somata surrounded by more complex basket axon terminal branches is blocked by TTX treatment between EP18 and EP24 ( $\chi^{2}$ test; $\left.p<0.001\right)$. However, TTX treatment between EP24 and EP28 has no effect ( $\chi^{2}$ test; $p=0.9$ ), suggesting that, once extended, basket terminal branches can be maintained around pyramidal cell soma despite reduced level of activity. (2-E2, An alternative method to quantify basket axon terminal complexity around pyramidal cell soma, by plotting of the number of intersections between basket axons and Sholl spheres with increasing radius from the center of a pyramidal nucleus. TTX treatment between EP18 and EP24 dramatically reduces the number of intersections and therefore the complexity of basket axon branches close to pyramidal cell soma.

cal and histochemical features characteristic to mature GABAergic neurons in vivo are either absent or significantly delayed (Benson and Cohen, 1996; Brunig et al., 2002). Therefore, the preservation of intact neuronal architecture and connectivity in organotypic cultures may be essential for the proper expression of molecular cues and neural activity patterns, which promote the development of GABAergic interneurons.

Because the level of neural activity in organotypic cultures is likely different from that in the visual cortex, it may seem surprising that the formation of perisomatic synapses proceeded in organotypic cultures with a time course not significantly different from that in vivo. A plausible explanation is that the developmental mechanisms driving the formation of perisomatic synapses, when subjected to different levels of neuronal activity at early postnatal ages (i.e., when organotypic cultures were prepared), can adapt and proceed, to some extent, with an intrinsic pace. Indeed, cortical organotypic cultures steadily increase the levels of spontaneous neuronal activity (Echevarria and Albus, 2000). In addition, the time course of the developmental increase of BDNF expression in organotypic cultures parallels that in the visual cortex (Gorba et al., 1999). On the other hand, our data show that maturation of perisomatic synapse during later postnatal weeks are sensitive to changes in level and pattern of neuronal activity both in organotypic cultures and in the visual cortex.

Formation of perisomatic synapses is regulated by neuronal activity, a link between cortical intrinsic and experience-dependent mechanisms Neuronal activity has shown to regulate the density of GABAergic synapses in the hippocampus assayed by electron microscopy (Marty et al., 2000). The role of activity in the formation of perisomatic synapses in neocortex has not been investigated because of the lack of specific markers. Here, we show that perisomatic synapse formation involved a stereotyped morphogenic process that included the extension of distinct axon terminal forks and the proliferation and enlargement of boutons around pyramidal cell soma, each with a reliable developmental time course. These characteristics allowed us to examine not only whether perisomatic synapse formation in general, but also whether the specific morphogenic events, in particular, are sensitive to activity regulation. First, we found that reduction of the activity level by TTX treatment blocked the progression of all the above morphogenic events that we have observed, suggesting that neuronal firing promotes perisomatic synapse formation. Second, the window of sensitivity for activity regulation is different for different morphogenic events. The formation of axon terminal forks around pyramidal neurons was essentially prevented by TTX treatment. However, once formed, terminal branches were maintained even with reduced levels of neuronal activity. In contrast, the proliferation of synaptic boutons around pyramidal cell soma continued after terminal branch formation and remained sensitive to activity levels.

Such activity-regulated perisomatic synapse formation can impact at least two aspects of perisomatic innervation within cortical circuits. First, the activity-dependent progression of perisomatic synapse formation can influence the time course and therefore the maturation of perisomatic innervation among pyramidal neurons. Second, the activity-dependent regulation of perisomatic boutons can influence the pattern of perisomatic innervation among pyramidal neurons. Because the level and pattern of neuronal activity in the primary visual cortex is strongly influenced by sensory input, this activity-regulated process of perisomatic synapses formation establishes a natural link between the experience-dependent and cortical intrinsic mechanisms underlying the development of perisomatic innervation in the visual cortex.

\section{Maturation of perisomatic innervation in visual cortex is} regulated by sensory experience during a critical period Dark rearing from birth results in profound deficits in receptive field properties of visual cortical neurons (Benevento et al., 1992; 
Fagiolini et al., 1994; Gianfranceschi et al., 2003) and retardation of GABAergic inhibition (Morales et al., 2002). In addition, monocular deprivation during a critical period alters the ocular dominance of visual cortical neurons (Gordon and Stryker, 1996). The effects of visual deprivation on GABA synthesis have been studied in several species with conflicting results. In primate and rodent primary visual cortex, reduced sensory inputs leads to reduction in the expression of GAD and GABA (Hendry and Jones, 1986; Benevento et al., 1995). In cats, in contrast, neither the number of GAD-expressing neurons nor levels of GAD protein expression are reduced by dark rearing or monocular deprivation (Guo et al., 1997; Mower et al., 2001). Although species differences could be genuine, the discrepancies may also reflect the heterogeneity of GABAergic neurons in response to deprivation and the poor sensitivity of detection method. In addition, none of these previous studies directly examined GABAergic synapses and, in particular, perisomatic synapses because of the lack of specific markers.

Here, we demonstrate a significant and reliable reduction of perisomatic innervation by visual deprivation through shortterm monocular TTX injection. We cannot rule out the possibility that TTX also reduced the extension of basket axon terminal branches. Interestingly, the effects of visual deprivation are only seen in the third, but not the fifth, postnatal week. These results therefore suggest that the maturation and pattern of perisomatic innervation in the primary visual cortex are effectively regulated by experience-driven input activity only during a restricted postnatal time window. To our knowledge, this is the first report of a sensitive period for anatomical plasticity within rodent primary visual cortex. The specific genetic labeling of the Pv class of basket interneurons may be necessary to detect plasticity of perisomatic innervation. These results are consistent with physiological findings (Morales et al., 2002) showing that dark rearing retards maturation of GABAergic inhibition only when initiated at birth but not after the third postnatal week. It is not clear whether the CCK class of perisomatic synapses is also influenced by visual deprivation.

A reduction of perisomatic innervation after visual deprivation can have a profound impact on receptive field properties and structural and functional rearrangement of neuronal circuits in the primary visual cortex. For example, decreased perisomatic innervation could contribute to reduced GABAergic inhibition and enlargement of receptive field size after dark rearing (Benevento et al., 1992). Maturation of GABAergic inhibition has been implicated in both the onset and the closure of the critical period of ocular dominance plasticity (Hanover et al., 1999; Huang et al., 1999; Fagiolini and Hensch, 2000; Kirkwood and Bear, 1994), but the specific class of GABAergic synapses and mechanisms involved are unclear. Here, we show that the maturation of perisomatic innervation parallels the onset and progression of the critical period of OD plasticity and is influenced by monocular deprivation during a restricted time window, before the peak of OD plasticity. These results implicate the morphological maturation of perisomatic synapses as a component of GABAergic function, which may contribute to the onset of OD plasticity.

\section{References}

Bahr S, Wolff JR, Brunig I, Scotti E, Sidler C, Fritschy JM (1985) Postnatal development of axosomatic synapses in the rat visual cortex: morphogenesis and quantitative evaluation. J Comp Neurol 233:405-420.

Benevento LA, Bakkum BW, Port JD, Cohen RS (1992) The effects of darkrearing on the electrophysiology of the rat visual cortex. Brain Res 572:198-207.
Benevento LA, Bakkum BW, Cohen RS, Port JD (1995) Gammaaminobutyric acid and somatostatin immunoreactivity in the visual cortex of normal and dark-reared rats. Brain Res 689:172-182.

Benson DL, Cohen PA (1996) Activity-independent segregation of excitatory and inhibitory synaptic terminals in cultured hippocampal neurons. J Neurosci 16:6424-6432.

Brunig I, Scotti E, Sidler C, Fritschy JM (2002) Intact sorting, targeting, and clustering of gamma-aminobutyric acid A receptor subtypes in hippocampal neurons in vitro. J Comp Neurol 443:43-55.

Caleo M, Lodovichi C, Maffei L (1999) Effects of nerve growth factor on visual cortical plasticity require afferent electrical activity. Eur J Neurosci 11:2979-2984.

Chan CH, Godinho LN, Thomaidou D, Tan SS, Gulisano M, Parnavelas JG (2001) Emx1 is a marker for pyramidal neurons of the cerebral cortex. Cereb Cortex 11:1191-1198.

De Simoni A, Griesinger CB, Edwards FA (2003) Development of rat CA1 neurons in acute versus organotypic slices: role of experience in synaptic morphology and activity. J Physiol (Lond) 550:135-147.

Di Cristo G, Wu C, Chattopadhyaya B, Agno F, Knott G, Welker E, Svoboda K, Huang ZJ (2004) Subcellular domain-restricted GABAergic innervation in primary visual cortex in the absence of sensory and thalamic input. Nat Neurosci, in press.

Echevarria D, Albus K (2000) Activity-dependent development of spontaneous bioelectric activity in organotypic cultures of rat occipital cortex. Brain Res Dev Brain Res 123:151-164.

Fagiolini M, Hensch TK (2000) Inhibitory threshold for critical-period activation in primary visual cortex. Nature 404:183-186.

Fagiolini M, Pizzorusso T, Berardi N, Domenici L, Maffei L (1994) Functional postnatal development of the rat primary visual cortex and the role of visual experience: dark rearing and monocular deprivation. Vision Res 34:709-720.

Freund TF (2003) Interneuron diversity series: rhythm and mood in perisomatic inhibition. Trends Neurosci 26:489-495.

Freund TF, Buzsaki G, White BH, Osterwalder TP, Yoon KS, Joiner WJ, Whim MD, Kaczmarek LK, Keshishian H (1996) Interneurons of the hippocampus. Hippocampus 6:347-470.

Gianfranceschi L, Siciliano R, Walls J, Morales B, Kirkwood A, Huang ZJ, Tonegawa S, Maffei L (2003) Visual cortex is rescued from the effects of dark rearing by overexpression of BDNF. Proc Natl Acad Sci USA 100:12486-12491.

Gorba T, Klostermann O, Wahle P (1999) Development of neuronal activity and activity-dependent expression of brain-derived neurotrophic factor mRNA in organotypic cultures of rat visual cortex. Cereb Cortex 9:864-877.

Gordon JA, Stryker MP (1996) Experience-dependent plasticity of binocular responses in the primary visual cortex of the mouse. J Neurosci 16:3274-3286.

Guo H, Hong S, Jin XL, Chen RS, Avasthi PP, Tu YT, Ivanco TL, Li Y (2000) Specificity and efficiency of Cre-mediated recombination in Emx1-Cre knock-in mice. Biochem Biophys Res Commun 273:661-665.

Guo Y, Kaplan IV, Cooper NG, Mower GD (1997) Expression of two forms of glutamic acid decarboxylase (GAD67 and GAD65) during postnatal development of the cat visual cortex. Brain Res Dev Brain Res 103:127-141.

Gupta A, Wang Y, Markram H (2000) Organizing principles for a diversity of GABAergic interneurons and synapses in the neocortex. Science 287:273-278.

Hanover JL, Huang ZJ, Tonegawa S, Stryker MP, Benevento LA, Bakkum BW, Port JD, Cohen RS (1999) Brain-derived neurotrophic factor overexpression induces precocious critical period in mouse visual cortex. J Neurosci 19:RC40 (1-5).

Heintz N, De Felipe J, Marco P, Fairen A, Jones EG (2001) BAC to the future: the use of bac transgenic mice for neuroscience research. Nat Rev Neurosci 2:861-870.

Hendry SH, Jones EG (1986) Reduction in number of immunostained GABAergic neurones in deprived-eye dominance columns of monkey area 17. Nature 320:750-753.

Holmgren C, Harkany T, Svennenfors B, Zilberter Y (2003) Pyramidal cell communication within local networks in layer $2 / 3$ of rat neocortex. J Physiol (Lond) 551:139-153.

Huang ZJ, Kirkwood A, Pizzorusso T, Porciatti V, Morales B, Bear MF, Maffei 
L, Tonegawa S (1999) BDNF regulates the maturation of inhibition and the critical period of plasticity in mouse visual cortex. Cell 98:739-755.

Jeong SY, Goto J, Hashida H, Suzuki T, Ogata K, Masuda N, Hirai M, Isahara K, Uchiyama Y, Kanazawa I (2000) Identification of a novel human voltage-gated sodium channel alpha subunit gene, SCN12A. Biochem Biophys Res Commun 267:262-270.

Jin X, Hu H, Mathers PH, Agmon A (2003) Brain-derived neurotrophic factor mediates activity-dependent dendritic growth in nonpyramidal neocortical interneurons in developing organotypic cultures. J Neurosci 23:5662-5673.

Kirkwood A, Bear MF (1994) Hebbian synapses in visual cortex. J Neurosci 14:1634-1645.

Klausberger T, Magill PJ, Marton LF, Roberts JD, Cobden PM, Buzsaki G, Somogyi P (2003) Brain-state- and cell-type-specific firing of hippocampal interneurons in vivo. Nature 421:844-848.

Klostermann O, Wahle P (1999) Patterns of spontaneous activity and morphology of interneuron types in organotypic cortex and thalamus-cortex cultures. Neuroscience 92:1243-1259.

Lee EC, Yu D, Martinez de Velasco J, Tessarollo L, Swing DA, Court DL, Jenkins NA, Copeland NG (2001) A highly efficient Escherichia colibased chromosome engineering system adapted for recombinogenic targeting and subcloning of BAC DNA. Genomics 73:56-65.

Marty S, Wehrle R, Sotelo C, Guo Y, Kaplan IV, Cooper NG, Mower GD (2000) Neuronal activity and brain-derived neurotrophic factor regulate the density of inhibitory synapses in organotypic slice cultures of postnatal hippocampus. J Neurosci 20:8087-8095.

McBain CJ, Fisahn A (2001) Interneurons unbound. Nat Rev Neurosci 2:11-23.

Miles R, Toth K, Gulyas AI, Hajos N, Freund TF (1996) Differences between somatic and dendritic inhibition in the hippocampus. Neuron $16: 815-823$.

Miller MW (1986) Maturation of rat visual cortex. III. Postnatal morphogenesis and synaptogenesis of local circuit neurons. Brain Res 390:271-285.

Morales B, Choi SY, Kirkwood A (2002) Dark rearing alters the development of GABAergic transmission in visual cortex. J Neurosci 22:8084-8090.

Mower GD, Guo Y (2001) Comparison of the expression of two forms of glutamic acid decarboxylase (GAD67 and GAD65) in the visual cortex of normal and dark-reared cats. Brain Res Dev Brain Res 126:65-74.

Ruthazer ES, Cline HT (2002) Multiphoton imaging of neurons in living tissue:acquisition and analysis of time-lapse morphological data. RealTime Imaging 8:175-188.

Somogyi P, Tamas G, Lujan R, Buhl EH (1998) Salient features of synaptic organisation in the cerebral cortex. Brain Res Brain Res Rev 26:113-135.

Stoppini L, Buchs PA, Muller D (1991) A simple method for organotypic cultures of nervous tissue. J Neurosci Methods 37:173-182.

Tamas G, Buhl EH, Somogyi P (1997) Fast IPSPs elicited via multiple synaptic release sites by different types of GABAergic neurone in the cat visual cortex. J Physiol (Lond) 500:715-738.

Tamas G, Lorincz A, Simon A, Szabadics J (2003) Identified sources and targets of slow inhibition in the neocortex. Science 299:1902-1905.

Wang Y, Gupta A, Toledo-Rodriguez M, Wu CZ, Markram H (2002) Anatomical, physiological, molecular and circuit properties of nest basket cells in the developing somatosensory cortex. Cereb Cortex 12:395-410.

Yang XW, Model P, Heintz N (1997) Homologous recombination based modification in Escherichia coli and germline transmission in transgenic mice of a bacterial artificial chromosome. Nat Biotechnol 15:859-865. 